\title{
NUNCA ES TARDE PARA VOLVER A LA ESCUELA Resultados de la encuesta del UIS sobre programas de educación de adultos y alfabetización en América Latina y el Caribe
}




\section{UNESCO}

La Constitución de la Organización de las Naciones Unidas para la Educación, la Ciencia y la Cultura (UNESCO) fue aprobada por 20 países en la Conferencia de Londres, en noviembre de 1945, y entró en vigor el 4 de noviembre de 1946. La Organización cuenta actualmente con 195 Estados Miembros y 8 Miembros Asociados.

El principal objetivo de la UNESCO es contribuir a la paz y la seguridad en el mundo promoviendo, mediante la educación, la ciencia, la cultura y la comunicación, la colaboración entre las naciones, a fin de asegurar el respeto universal de la justicia, el estado de derecho, los derechos humanos y las libertades fundamentales que la Carta de las Naciones Unidas reconoce a todos los pueblos del mundo sin distinción de raza, sexo, idioma o religión.

Para cumplir este mandato, la UNESCO desempeña cinco funciones principales: 1) estudios prospectivos sobre la educación, la ciencia, la cultura y la comunicación para el mundo del mañana; 2) el fomento, la transferencia y el intercambio del conocimiento mediante actividades de investigación, formación y educativas; 3) acciones normativas, para la preparación y aprobación de instrumentos internos y recomendaciones estatutarias; 4) conocimientos especializados que se transmiten a los Estados Miembros mediante cooperación técnica para que elaboren sus políticas y proyectos de desarrollo; y 5) el intercambio de información especializada.

La Sede de la UNESCO se encuentra en París, Francia.

\section{Instituto de Estadística de la UNESCO}

El Instituto de Estadística de la UNESCO (UIS) es la oficina de estadística de la UNESCO y es el depositario de la ONU en materia de estadísticas mundiales en los campos de la educación, la ciencia y la tecnología la cultura y la comunicación.

EI UIS fue fundado en 1999. Se creó con el fin de mejorar el programa de estadística de la UNESCO, así como para desarrollar y suministrar estadísticas exactas, oportunas y políticamente relevantes, requeridas en un contexto actual cada vez más complejo y rápidamente cambiante.

La Sede del UIS se encuentra en Montreal, Canadá.

Publicado en 2013 por:

Instituto de Estadística de la UNESCO

C.P. 6128, Succursale Centre-Ville

Montréal, Québec H3C 3J7

Canada

Tel: +1 514-343-6880

Correo electrónico: uis.publications@unesco.org

http://www.uis.unesco.org

ISBN 978-92-9189-143-6

Ref: UIS/2013/ED/TD/08

(C) UNESCO-UIS 2013

Las ideas y opiniones expuestas en esta obra son las propias de sus autores y no reflejan necesariamente las de la UNESCO. Las denominaciones empleadas en esta publicación y la presentación de los datos que en ella figuran no implican, por parte de la UNESCO, ninguna toma de posición respecto al estatuto jurídico de los países, ciudades, territorios o zonas, o de sus autoridades, ni respecto al trazado de sus fronteras o límites. 


\section{Agradecimientos}

Este documento fue elaborado por Isabel Infante, María Eugenia Letelier y José Rivero, consultores independientes especialistas en la temática de educación de adultos. Se contó además con la colaboración de Hanna Taleb, asistente de estadística del UIS, para la elaboración de los cuadros; y el informe fue revisado y finalizado por Amélie Gagnon, Juan Cruz Perusia y Alejandro Vera, especialistas del Instituto de Estadística de la UNESCO (UIS). 


\section{Índice}

Página

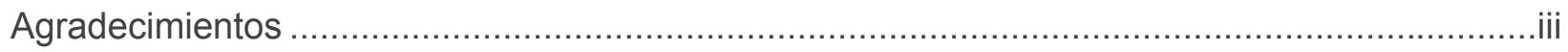

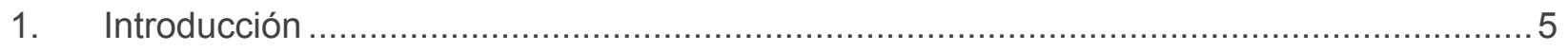

2. La importancia de la educación de personas jóvenes y adultas ......................................

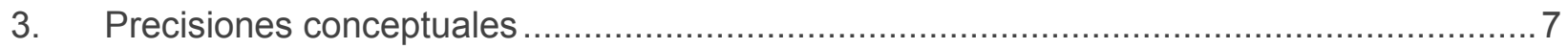

4. Análisis de los resultados de la encuesta.................................................................. 10

4.1. La importancia de contar con estadísticas referidas a la educación de

4.2. Visión general sobre alfabetismo en la región ..................................................11

4.3. Ofertas de programas de alfabetización en América Latina y el Caribe ................12

4.4. Logros educativos de la población joven y adulta en la región..............................18

4.5. Participación en educación primaria y secundaria de adultos ..............................20

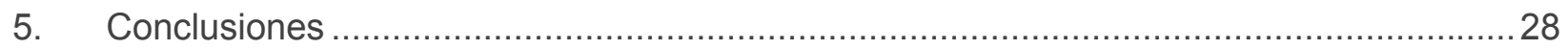

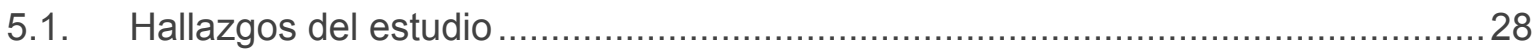

5.2. Prioridades para un desarrollo estadístico futuro..............................................30

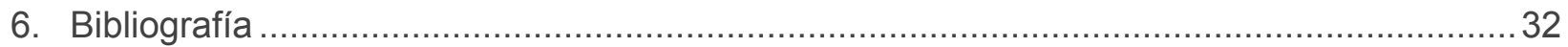

Anexo I. Alcance, estructura y cobertura de la Encuesta Regional de Estadísticas de Educación de Adultos para América Latina y el Caribe............................................34

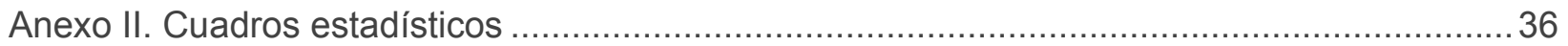




\section{Introducción}

Entre los compromisos adoptados por la VI Conferencia Internacional de Educación de Adultos realizada en Belém, Brasil (2009), se planteó "reunir y analizar sistemáticamente datos e información sobre la participación y la evolución de los programas de educación de adultos, desglosados por sexo y otros factores, para evaluar el cambio a lo largo del tiempo y compartir prácticas idóneas".

Para incrementar la disponibilidad de estadísticas en un área en la que existían muchas debilidades a nivel internacional comparado, contribuyendo así a asumir los dictados de la CONFINTEA VI, el Instituto de estadística de la UNESCO (UIS) optó por organizar una encuesta, en colaboración con los países de América Latina y el Caribe, que posibilitara incrementar el alcance y la disponibilidad de información relevante y comparable sobre la participación de jóvenes y adultos en programas educativos específicos. Sería un primer paso para mejorar la cobertura de las estadísticas de la educación de adultos.

Con este objetivo, se implementó en 2011 una encuesta regional de estadísticas de educación de adultos en América Latina y el Caribe, proporcionando las definiciones necesarias para ejecutar la recolección de datos. El instrumento fue respondido con datos válidos por 30 de los 43 países y territorios, que representan el $98 \%$ de la población regional.

El presente informe tiene como objetivo analizar los resultados de la encuesta regional de estadísticas de educación de adultos y relevar las principales conclusiones que se desprenden de ellos.

El documento comprende cinco capítulos: los dos primeros tienen como objetivo contextualizar la encuesta, el tercero precisa los términos que se emplean en la educación de personas jóvenes y adultas, el cuarto presenta un análisis de los resultados y el último, señala algunas conclusiones. En el Anexo se resume el alcance, metodología y cobertura de la encuesta y se presentan los cuadros estadísticos.

\section{La importancia de la educación de personas jóvenes y adultas}

En América Latina y el Caribe, al igual que en otras regiones en desarrollo, se plantea recurrentemente la importancia del sistema educativo como elemento esencial para mejorar la competitividad. Así, en un contexto de globalización, de cambios vertiginosos que afectan todas las esferas de la vida y de sociedades caracterizadas por grandes grupos de población considerables que en el pasado tuvieron muchas menos oportunidades educativas que las que hoy existen, la modalidad de la educación de personas jóvenes y adultas (EPJA) se convierte en elemento crucial.

Por otra parte, un conjunto de hechos y procesos documentarios institucionales de nivel internacional ha significado para la educación de personas jóvenes y adultas un verdadero desafío para su conceptualización y para un ajuste de sus prácticas. 
Las políticas internacionales sobre educación de personas jóvenes y adultas han sido influenciadas en la región por cinco hitos: la Conferencia Mundial de Educación para Todos (Jomtien, 1990); el Informe Educación para el Siglo XXI elaborado por la Comisión Delors (1996); la Conferencia Internacional de Educación de Adultos (CONFINTEA) V (Hamburgo, 1997), el Foro Mundial sobre Educación (Dakar, 2000) y la CONFINTEA VI (Belém do Pará, 2009).

La Conferencia Mundial desarrollada en Jomtien demandó la satisfacción de necesidades básicas de aprendizaje de niños, jóvenes y adultos en diferentes ámbitos. Señaló que las necesidades abarcan tanto las herramientas esenciales para el aprendizaje como los contenidos básicos necesarios para que los seres humanos "puedan sobrevivir, desarrollar plenamente sus capacidades, vivir y trabajar con dignidad, participar plenamente en el desarrollo, mejorar la calidad de su vida, tomar decisiones fundamentadas y continuar aprendiendo. La amplitud de las necesidades básicas de aprendizaje y la manera de satisfacerlas varían según cada país y cada cultura y cambian inevitablemente con el transcurso del tiempo" (Declaración mundial sobre Educación para Todos, Jomtien, 1990).

El Informe de la Comisión Delors fue elaborado pensando en el siglo XXI. En el informe, aparte de los cuatro pilares que se proponen para toda educación (aprender a ser, a conocer, a hacer y a convivir), se puso énfasis particular en un aprendizaje a lo largo de toda la vida. Señala textualmente que de la educación depende, en gran medida, el progreso de la humanidad y toda forja de futuro.

CONFINTEA $V$ fue un espacio en que se reconoció la presencia juvenil como actor de la EPJA y se ubicó a la educación a lo largo de la vida no sólo como un derecho humano básico, sino como una de las claves del siglo XXI. "La educación de adultos puede configurar la identidad y dar significado a la vida. Aprender durante toda la vida significa replantear los contenidos de la educación a fin de que reflejen factores tales como la edad, la igualdad entre hombres y mujeres, las discapacidades, el idioma, la cultura y las disparidades económicas" (Declaración de Hamburgo, CONFINTEA V ).

En la Conferencia Internacional de Dakar se hicieron fundadas críticas al no cumplimiento de la educación para todos acordada en Jomtien y se demandó rescatar a la EPJA como prioridad mundial, integrándose la alfabetización y los demás programas a las reformas educativas denominadas de segunda generación, conservando sus especificidades. Entre los objetivos se acordó "aumentar de aquí al año 2015 el número de adultos alfabetizados en un 50\%, en particular tratándose de mujeres, y facilitar a todos los adultos un acceso equitativo a la educación básica y la educación permanente" (Marco de acción de Dakar, 2000).

CONFINTEA VI tuvo como objetivos: promover el reconocimiento del aprendizaje a lo largo de toda la vida, cuyo fundamento es la alfabetización; destacar el papel decisivo que han de desempeñar el aprendizaje y la educación en la realización de los programas internacionales actuales de educación y desarrollo; dar un nuevo impulso al compromiso político en este ámbito y preparar instrumentos de información que permitieran pasar de la retórica a la acción. El Marco de Acción de Belém fue aceptado como guía para aprovechar el poder y el potencial del aprendizaje de adultos para un futuro viable para todos.

La comprensión del papel de la educación de personas jóvenes y adultas ha cambiado y se ha desarrollado con el tiempo. Superando anteriores concepciones, hoy, en el contexto de un aprendizaje a lo largo de la vida, se percibe como una clave en la transformación económica, política y cultural de las personas, las comunidades y las sociedades en el siglo XXI. En 
América Latina y el Caribe es respuesta a una dramática situación de pobreza y exclusión; con ella se intenta enfrentar una secular postergación educativa económica y cultural de considerables núcleos de población; en algunos casos deviene en educación para la sobrevivencia.

\section{Precisiones conceptuales}

Como marco para los análisis de la encuesta, conviene precisar los diferentes conceptos referidos a educación de personas jóvenes y adultas, aludiendo también a su evolución.

\section{a) Educación de personas jóvenes y adultas}

En la última Conferencia Internacional sobre Educación de Adultos (CONFINTEA VI, Belém 2009) se suscribe la definición de educación de adultos, establecida por primera vez en Nairobi (1976), señalando que ésta denota "el conjunto de procesos de aprendizaje, formal o no, gracias al cual las personas cuyo entorno social considera adultos, desarrollan sus capacidades, enriquecen sus conocimientos y mejoran sus competencias técnicas o profesionales o las reorientan a fin de atender sus propias necesidades y las de la sociedad".

Al referirse a las personas "cuyo entorno social considera adultos" incluye de alguna manera a los jóvenes que, por diversos motivos, participan en una educación diferente a la regular de niños.

Por otra parte, teniendo en cuenta los cambios mundiales en el ámbito laboral, las nuevas tecnologías de información y comunicación (TIC), la creciente importancia del tema de la multiculturalidad, la presencia mayoritaria de jóvenes como sujetos de estos programas, así como la situación de la alfabetización y la educación básica en el mundo, se elaboró en América Latina con el liderazgo de la UNESCO la propuesta de educación de personas jóvenes y adultas (EPJA) ${ }^{1}$.

La redefinición y reflexión sobre el alcance de la EPJA tiene vinculación con una atención prioritaria a temas como los siguientes: (i) el compromiso prioritario de la EPJA para los sectores excluidos, sin posponer el trabajo con otros grupos de personas jóvenes y adultas; (ii) la EPJA y sus relaciones con la formación profesional, ya sea que se integren a los componentes curriculares o a las instituciones; (iii) atender particularmente la formación de jóvenes y adultos como ciudadanos con creciente autonomía, con capacidad de organización y participación en sus propios espacios y de establecer formas de convivencia solidarias; (iv) fortalecer las vinculaciones y los compromisos compartidos entre el Estado y la sociedad civil.

\section{b) Aprendizaje a lo largo de la vida}

El cambio de "educación" a "aprendizaje" constituye una transformación importante en la conceptualización del campo. El aprendizaje de adultos promueve procesos de educación formal, no formal e informal, a través de la vida del individuo. Con este aprendizaje se amplía considerablemente el horizonte de lo que se identifica con educación, con institución educativa y con mecanismos de aprendizaje.

1 Durante el proceso de elaboración del informe regional preparatorio a CONFINTEA VI se organizó una consulta en línea sobre el tema y se concluyó que el término por utilizar debía ser educación de personas jóvenes y adultas (EPJA), que es el que ha venido utilizándose en América Latina en los documentos de seguimiento de CONFINTEA V. Ver Torres, R.M. (2009). 
El aprendizaje permanente constituye en la actualidad el principio rector de las estrategias de política para alcanzar objetivos que incluyen desde el bienestar económico de los países y la competitividad hasta la realización personal y la cohesión social. Las teorías y modelos sobre cómo podría ser el aprendizaje en una sociedad del conocimiento abarcan propuestas que se rigen por la lógica del mercado y de la utilidad económica hasta aquellas cuyo principal objetivo es el bienestar personal, la participación activa en la vida ciudadana y la potenciación del individuo para que pueda elegir su trayectoria. (OIT, 1998).

Las demandas que esta sociedad realiza a todas las personas se refieren a competencias claves que permitan el aprendizaje permanente, el "aprender a aprender", la posibilidad y los medios de buscar y aprovechar la información existente, el desempeño de calidad, un manejo responsable de su vida en relación consigo mismo, con los demás, con la sociedad, con el medio ambiente. De ahí que el "aprender a vivir juntos" constituya una demanda fundamental de los tiempos actuales, que se expresa en el conocimiento de los demás, en la construcción de proyectos comunes, de solución pacífica de conflictos, en un análisis compartido de los riesgos y retos del futuro. (Delors, UNESCO, 1996).

\section{c) Alfabetismo, analfabetismo y alfabetización}

Alfabetismo como concepto - y analfabetismo como su expresión negativa - se ha definido e interpretado de múltiples maneras que han evolucionado en el tiempo bajo la influencia de trabajos de investigación, de conferencias internacionales y las prioridades en materia de políticas nacionales e internacionales

"Alfabetización" se refiere a la acción de alfabetizar. Por ello, el manejo efectivo del código de la escritura se ha designado como "alfabetismo", aunque en algunos contextos, "alfabetización" y "alfabetismo" aparecen como sinónimos.

El término alfabetismo, referido a las competencias de lectura y escritura, se entiende como un continuum que puede desarrollarse a lo largo de toda la vida. En él se pueden distinguir distintos niveles de dominio de las competencias.

El alfabetismo se relaciona con la práctica social de leer y escribir exigida en una sociedad y en una cultura determinada; se inscribe, por ello, dentro del conjunto de las prácticas que crean y reproducen la distribución social del conocimiento. Se puede decir que un alto nivel de alfabetismo está asociado a la posibilidad de aplicar las competencias de lectoescritura para finalidades precisas en los contextos específicos en que se utilizan, los que determinan los tipos de habilidades requeridas

Sin embargo, a pesar del reconocimiento que el alfabetismo está asociado un conjunto de competencias que pueden estar desarrolladas en distintos niveles, la forma más común que aún hoy se utiliza para medirlo se basa en una concepción dicotómica de éste. Así, mayormente censos y encuestas de hogares implementan preguntas del tipo "¿Sabe leer y escribir?", que la persona entrevistada debe responder por "sí" o "no", dando esta respuesta las categorizaciones de "alfabetizado" o "analfabeto", respectivamente 2 .

2 El reconocimiento de la complejidad asociada a la medición de la alfabetización ha dado lugar a diversas iniciativas que buscan evaluar de una manera más precisa las competencias en alfabetismo de la población. Una de los proyectos más recientes en esa área es el Programa de Evaluación y Monitoreo de la Alfabetización (LAMP, por sus siglas en inglés). Para mayor información en esta temática, consultar UNESCO, 2009. 


\section{d) La educación básica}

En los años 90 en América Latina y el Caribe se identificó la educación básica con la primaria infantil, sin considerar la educación básica de jóvenes y adultos. Por ello importa rescatar una visión ampliada de dicha educación. La educación básica debe responder a las necesidades básicas de aprendizaje requeridas en el medio social y laboral. ${ }^{3}$

\section{e) La educación formal}

En el caso de jóvenes y adultos, la educación formal se desarrolla en ambientes institucionales dentro de sistemas regulares diseñados como un camino continuo de escolaridad. Su currículum se relaciona generalmente con el currículum de niños, relativamente adaptado para jóvenes y adultos y cuyos certificados son equivalentes a la educación regular del sistema escolar. Sus niveles corresponden a los de la Clasificación Internacional Normalizada de la Educación (CINE). Asisten a la educación formal de adultos aquellos que no tuvieron ninguna oportunidad de acceder en su momento a la escuela regular destinada a niños y adolescentes o, habiendo accedido, no pudieron finalizarla.

\section{f) La educación no formal}

La educación no formal varía considerablemente entre países. Sus programas, según los contextos nacionales, pueden ser "alternativos", "abiertos", "flexibles" "populares", "comunitarios". Dependiendo de cada contexto nacional pueden comprender programas de alfabetización, de educación básica, capacitación laboral, habilidades para la vida y desarrollo del conocimiento general. La CINE 2011 señala que "en general, la educación no formal conduce a certificaciones que no son reconocidas por las autoridades nacionales 0 subnacionales competentes como equivalentes a la educación formal. En ocasiones no otorga certificación alguna."

\section{g) La educación popular}

Es una corriente político-pedagógica en la que confluye una diversidad de prácticas educativas con identidad propia frente a otras maneras de ver y hacer educación. Su intencionalidad política, ética y pedagógica suele estar articulada a la transformación personal y social con una lectura crítica de la sociedad y de la educación tradicional. Las ideas y la obra de Paulo Freire sustentan su concepción y desarrollo.

3 Hay que precisar que en la Clasificación Internacional Normalizada de la Educación (CINE) del año 1997 se utiliza el concepto de educación "básica" como equivalente a los niveles 1 y 2 de dicha clasificación, que corresponden a la educación primaria y al primer ciclo de la educación secundaria. La duración de estos niveles varía por país, aunque la duración típica es de 9 años de escolaridad a partir del primero de educación primaria. Sin embargo, la nueva versión de la CINE, correspondiente al año 2011, ha suprimido el concepto de educación "básica" de la nomenclatura internacional, manteniéndolo solo como ejemplo de denominaciones nacionales para programas educativos que abarcan los niveles 1 y 2 . 


\section{Análisis de los resultados de la encuesta}

\subsection{La importancia de contar con estadísticas referidas a la educación de personas jóvenes y adultas}

El análisis de las características educativas de la población adulta se ha centrado primordialmente en observar la situación de alfabetismo y los niveles de estudio, en lo que se refiere al sistema educativo formal. Así, las estadísticas tradicionales más utilizadas en esta área son las tasas de alfabetización y los indicadores de logro educativo o máximo nivel educativo alcanzado. En la actualidad, casi todos los países cuentan con censos de población y encuestas de hogares que permiten producir estos indicadores con cierta regularidad.

Por otro lado, la consolidación de los sistemas de información educativa en las últimas décadas en América Latina y el Caribe ha posibilitado también contar con estadísticas del acceso a los sistemas educativos y de su funcionamiento en distintas dimensiones, principalmente para las ofertas educativas formales diseñadas para los niños y jóvenes que buscan transitar desde el nivel preprimario hasta la educación terciaria.

Sin embargo, los sistemas de información respecto de las ofertas de educación de adultos están menos desarrollados. Cuando las estadísticas están disponibles, se refieren sólo a las modalidades que conducen a certificación formal, aun cuando la oferta de educación de adultos incluye una amplia gama de programas y modalidades organizadas con diferentes propósitos, alcances y extensión, muchas de los cuales no conducen a certificación escolar. Entre dichos programas se destacan los de formación para el trabajo, los programas o campañas de alfabetización o los ligados al desarrollo de competencias en áreas de salud y/o participación comunitaria.

A diferencia de la educación formal de niños y jóvenes, las ofertas educativas de adultos suelen tener diferente dependencia institucional. Algunas, como los programas o campañas de alfabetización, son implementadas desde los gabinetes de la presidencia o los ministerios de planificación social; a su vez, muchas ofertas de capacitación laboral se desarrollan desde los ministerios del trabajo. A estas ofertas es necesario incorporar los programas y acciones que se realizan desde la sociedad civil. Es decir, las ofertas de educación de adultos no dependen exclusivamente de los ministerios de educación, cuestión que evidencia su complejidad organizativa y supone así un desafío adicional en la construcción de estadísticas comparadas.

Todos estos factores inciden en la disponibilidad de información confiable, oportuna y accesible que permita fundamentar el diseño de políticas y planes de intervención en educación de personas jóvenes y adultas. Asumiendo el mandato de las conferencias internacionales y con el propósito de avanzar en la construcción de estadísticas comparables entre los países de América Latina y el Caribe, el UIS, elaboró y aplicó una encuesta regional sobre estadísticas de educación de adultos relacionada con los programas de alfabetización, educación primaria y secundaria.

En las próximas secciones se analizan los resultados de la encuesta respecto de la oferta de programas de alfabetización y respecto de las ofertas de educación primaria y secundaria de educación de personas jóvenes y adultas. Para una mayor comprensión, antecede al análisis de los resultados, una visión general sobre la situación de alfabetismo y sobre el logro educativo de la población. 


\subsection{Visión general sobre alfabetismo en la región}

Durante las últimas décadas, en América Latina y el Caribe, se puede verificar un avance moderado en los niveles de alfabetización de la población. La tasa de alfabetización de adultos (15 años y más) era de $86 \%$ en 1990 y se alcanzaba a $92 \%$ en 2011 . Tal como se puede apreciar en el Cuadro 1, esta tendencia sigue el comportamiento general observado a nivel mundial y aproxima a América Latina y el Caribe a las tasas de alfabetización registradas en regiones de mayor nivel de desarrollo.

Cuadro 1. Tasas de alfabetización de jóvenes y adultos (15 años y más) (\%), según región

\begin{tabular}{lrrr}
\hline Región & 1990 & $\mathbf{2 0 0 0}$ & $\mathbf{2 0 1 1}$ \\
\hline África Sub-Sahariana & 53 & 57 & 59 \\
Asia Central & 98 & 99 & 100 \\
Asía del Este y Pacífico & 82 & 92 & 95 \\
Asia Meridional y Occidental & 47 & 59 & 63 \\
América Latina y el Caribe & 86 & 90 & 92 \\
Estados Árabes & 55 & 68 & 77 \\
Europa Central y del Este & 96 & 97 & 99 \\
\hline
\end{tabular}

Fuente: UIS Information Paper: "Adult and youth literacy rates. National, regional and global trends, 19852015", junio de 2013.

A pesar de estos avances, es necesario destacar que la población analfabeta en la región alcanza un total de 35,9 millones de personas de 15 años o más. Al desagregar según sexo, se puede observar que 19,8 millones corresponden al segmento femenino de la población, lo que representa el 55\% del total. Gradualmente se ha avanzado en la tasa de alfabetización de las mujeres, disminuyendo la brecha respecto del sector masculino de la población regional.

El comportamiento de las tasas de analfabetismo en la región presenta significativas diferencias según los países. Como se puede observar en el Gráfico 1, Haití presenta una tasa mayor al $50 \%$, seguido por Guatemala y Nicaragua con valores que se sitúan en $24 \%$ y $22 \%$ respectivamente; en el otro extremo se puede observar que doce países registran tasas inferiores a $5 \%$.

Como es de esperar, al desagregar los datos según edad de la población, se verifica una fuerte correlación entre esta variable y el alfabetismo. Mientras que la tasa de alfabetización total de la población de 15 años y más para el 2011 alcanzaba en la región un 91,5\%; entre la población de 15 a 24 años se eleva a un 97,1\%, lo que implica la existencia de 3,1 millones de jóvenes analfabetos en América Latina y el Caribe. En este segmento de jóvenes, no se aprecian diferencias en la tasa de alfabetización entre mujeres y hombres.

En las zonas rurales y con alta presencia de población indígena, se registran las tasas más bajas de alfabetización. El aislamiento, situación de pobreza y la identidad cultural y lingüística propia de las comunidades explican en gran parte que, en estas zonas, el porcentaje de analfabetismo se eleve entre 3 y 4 veces por sobre el promedio regional. 
Gráfico 1. Tasa de analfabetismo de la población adulta (15 años y más) (\%), países de América Latina y el Caribe, 2005-2011

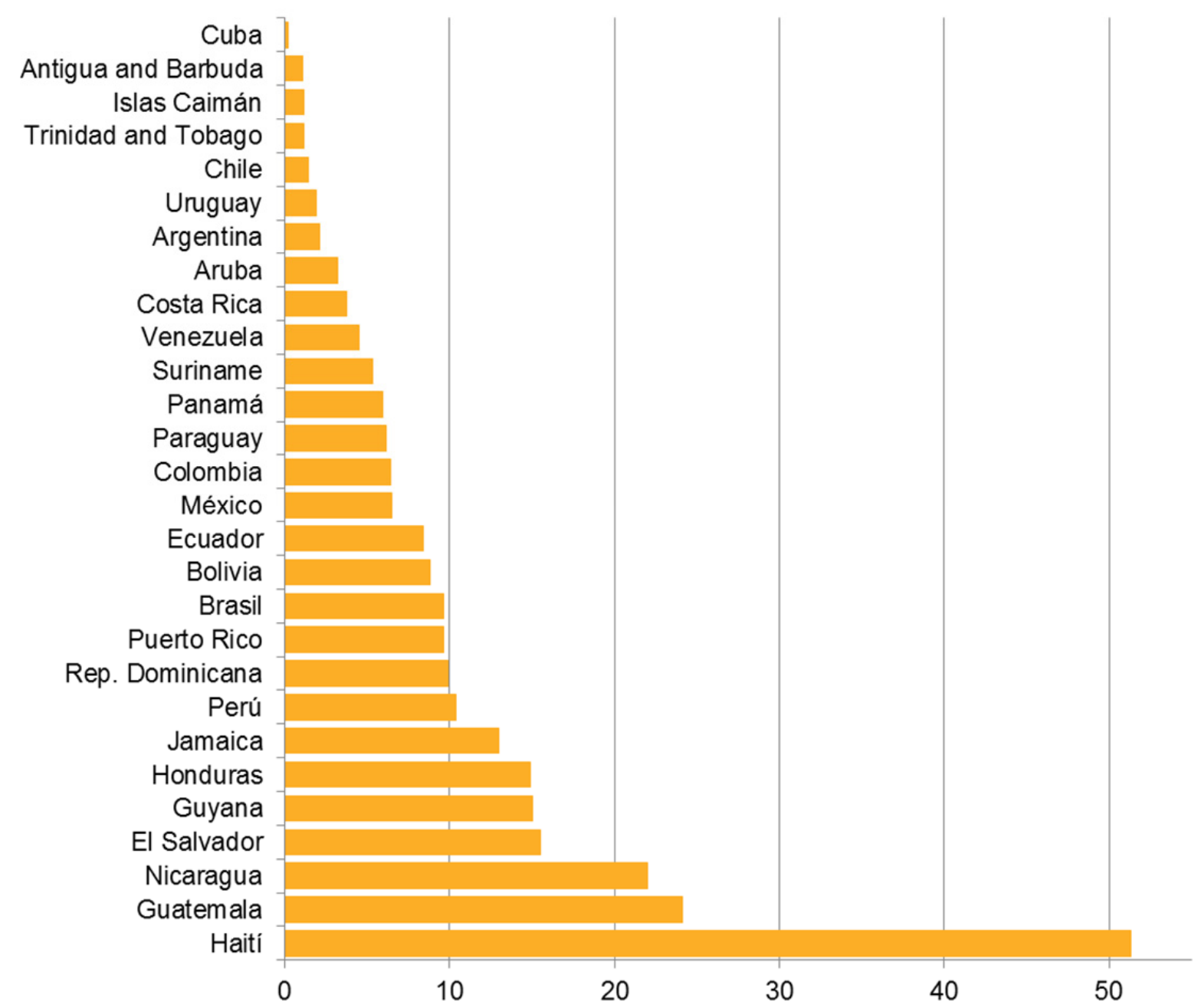

Fuente: Instituto de Estadística de la UNESCO, Centro de datos, mayo de 2013.

\subsection{Oferta de programas de alfabetización en América Latina y el Caribe}

La encuesta aplicada por el UIS permitió obtener información acerca de programas de alfabetización de 20 países de América Latina y el Caribe. Para el análisis de la oferta de alfabetización, se consideran tres variables: acceso, conclusión y duración de los programas.

En cuanto al acceso a programas de alfabetización, la información suministrada por los países consigna a un total de 2.529 .930 de jóvenes y adultos participantes ${ }^{4}$. El grupo de países que suministró información en relación a esta variable representa el $84 \%$ de la población total de América Latina y el Caribe. Por tanto, es dable pensar que esta cifra está subestimada si se piensa en relación al total de los países de la región.

4 La información corresponde al año 2010, o al año más reciente disponible. 
Un indicador que permite evaluar el grado de acceso de la población analfabeta a las ofertas de programas de alfabetización, lo constituye la relación entre el número de participantes de los programas en un período determinado y la población analfabeta registrada en el mismo período; en este caso, se utiliza como base el año 2010.

El Gráfico 2 presenta estos datos para el conjunto de países participantes de la encuesta que suministró esta información ${ }^{5}$.

Gráfico 2. Acceso a los programas de alfabetización, según países de América Latina y el Caribe (2010)

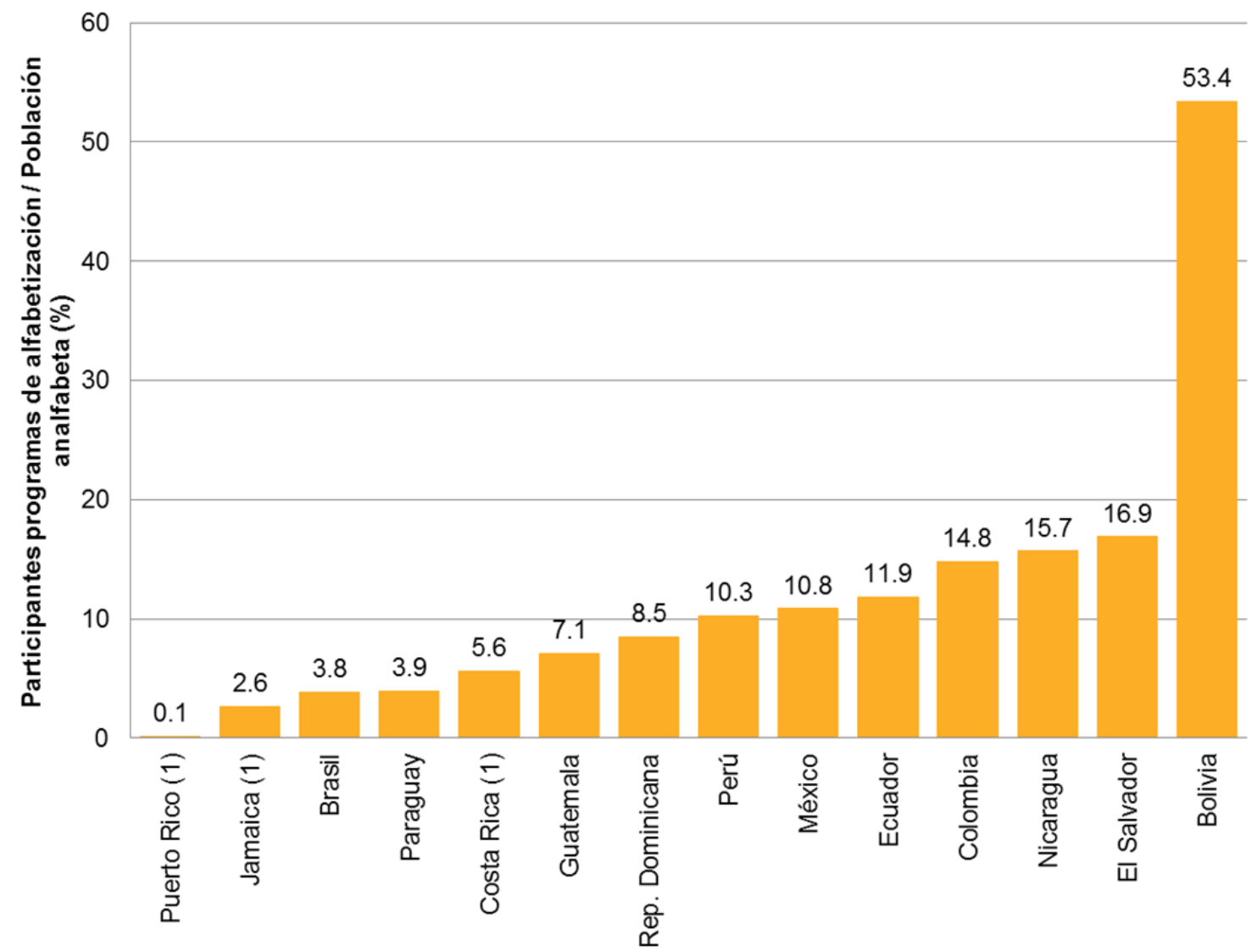

Notas: (1) Programas provistos solo por el sector público. El año de referencia para los datos de participantes es 2010, con excepción de Bolivia (2008), Brasil (2009) y Guatemala (2011).

Fuente: Instituto de Estadística de la UNESCO, Centro de datos, mayo de 2013 y Encuesta Regional de Estadísticas de Educación de Adultos 2011.

5 La cantidad de países para los cuales se ha calculado el indicador de acceso es menor al número de países que han reportado datos de participantes de programas de alfabetización debido a que no en todos los casos se cuenta con datos de la población analfabeta. En los cuadros estadísticos del Anexo puede consultarse la situación de cada país. 
Bolivia es el único país que registra un acceso a los programas de alfabetización de más de un $50 \%$ de la población analfabeta, seguido a distancia de países como El Salvador, Nicaragua, Colombia, Ecuador, México y Perú, los cuales registran entre un 10 y $17 \%$ de acceso a los programas de la población potencial que lo requiere.

El caso de Bolivia, con un alto nivel de acceso, corresponde al último año de implementación del Programa Nacional de Alfabetización, inspirado en la modalidad "Yo sí puedo", que estuvo vigente entre los años 2006 y 2008, con el que intentaba cubrir la totalidad de la población analfabeta.

Existe un conjunto de países que, si bien reportan datos de participación en programas de alfabetización, enfrentan una problemática considerada residual, pues han alcanzado elevados niveles de alfabetismo. Entre ellos Cuba, Antigua y Barbuda, Chile, Uruguay, Islas Caimán y Trinidad y Tobago, todos con tasas de alfabetización del $98 \%$ o más ${ }^{7}$.

Brasil registra un elevado número de participantes, 535.034 personas, que representa un 20\% del total de participantes en programas de alfabetización en la región. No obstante, los esfuerzos de este país en esta área persisten dado que esta cifra solo equivale al $3,8 \%$ de la población analfabeta.

Sobre el perfil de los participantes de programas de alfabetización, una característica notable es la elevada participación femenina. Como se puede observar en el Gráfico 3, para el total de países que han reportado datos el $65,5 \%$ de los participantes son mujeres. Este valor resulta más significativo si se piensa que las mujeres representan el $55,7 \%$ del total de la población analfabeta de la región.

La presencia femenina es particularmente elevada en países como Guatemala, Perú y México. Como es sabido, en la población indígena, las mujeres presentan mayores tasas de analfabetismo.

Las cifras de acceso analizadas previamente tienen limitaciones como medida "proxy" de superación del analfabetismo y una de las más evidentes es que el registro como participantes en un programa no garantiza la finalización con éxito del mismo.

Los niveles de conclusión con relación al número de participantes que inician los programas son diversos entre los países, pero en casi todos los casos es evidente la existencia de un problema muy serio de abandono. Así, puede observarse en el Gráfico 4, que de cada 10 personas que se registran en un programa de alfabetización en Nicaragua, Perú, El Salvador o República Dominicana, sólo entre 6 o 7 personas logra concluirlo. En los restantes países estos niveles son aún más bajos, con 4 países en donde menos de la mitad de las personas concluyen el programa.

6 "Yo sí puedo" es un programa de alfabetización desarrollado por el Instituto Pedagógico Latinoamericano y Caribeño (IPLAC) de Cuba, que combina números y letras para enseñar a leer y a escribir a personas adultas en el transcurso de 7 semanas, mediante la utilización de recursos audiovisuales como la televisión y reproductoras de video. El programa ha sido aplicado en varios países de América Latina y el Caribe.

7 No se ha incluido a estos países en el Gráfico 2, aunque el valor del indicador puede ser consultado en los cuadros estadísticos del Anexo. 
Gráfico 3. Porcentaje de mujeres en los participantes de programas de alfabetización, países de América Latina y el Caribe, 2010

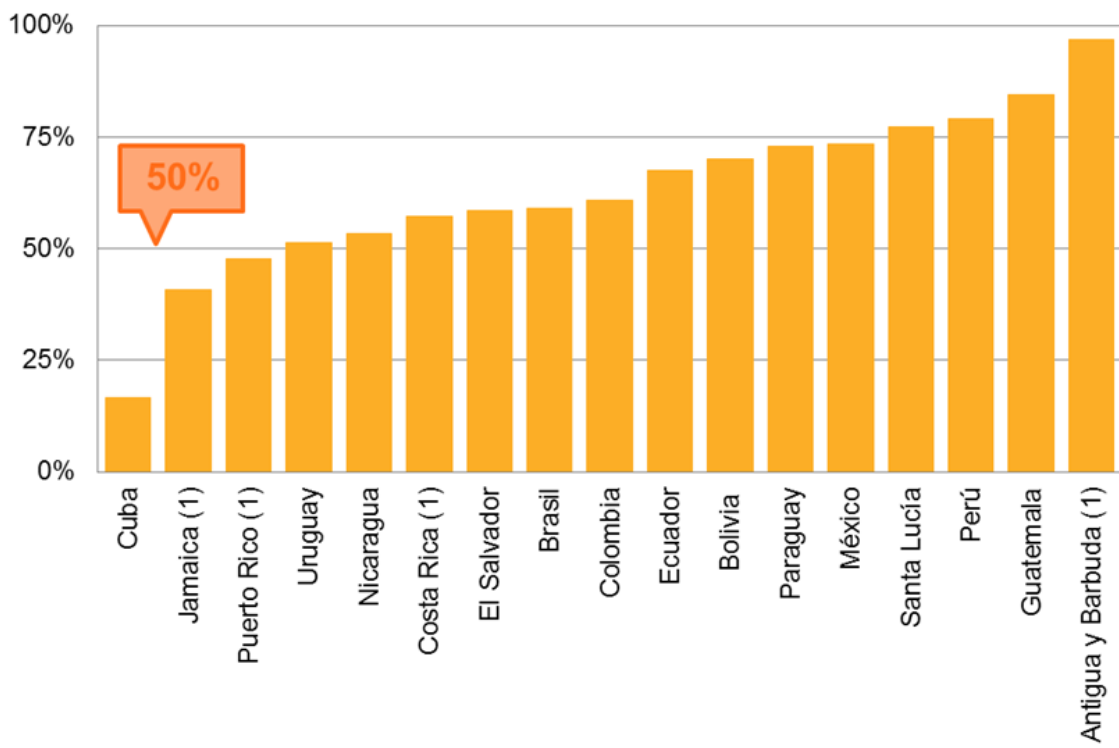

Notas: (1) Programas provistos solo por el sector público. El año de referencia para los datos de participantes es 2010, con excepción de Bolivia (2008), Brasil (2009) y Chile y Guatemala (2011). Fuente: Instituto de Estadística de la UNESCO y Encuesta Regional de Estadísticas de Educación de Adultos 2011.

Gráfico 4. Conclusión en los programas de alfabetización, países de América Latina y el Caribe, 2010

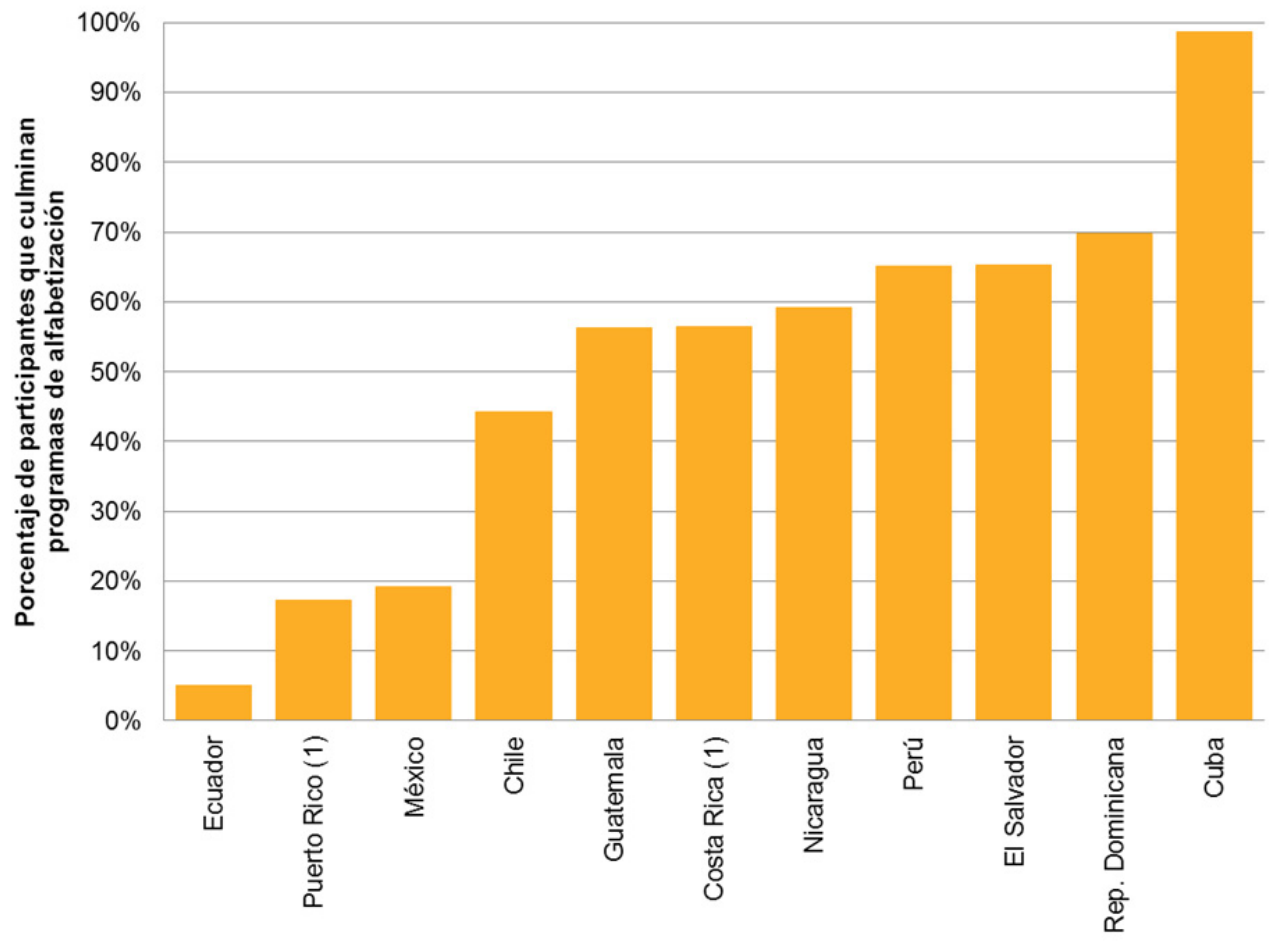

Notas: (1) Programas provistos solo por el sector público. El año de referencia para los datos de participantes es 2010, con excepción de Chile y Guatemala (2011).

Fuente: Instituto de Estadística de la UNESCO y Encuesta Regional de Estadísticas de Educación de Adultos 2011. 
De esta manera, tomando solo en cuenta el indicador que relaciona el número de participantes que han concluido el programa con la población objetivo, es decir, con la población analfabeta, los valores que se obtienen son mucho menores que los valores de acceso del Gráfico 2. Este indicador, que fluctúa entre valores menores al 1\% en Puerto Rico y Ecuador, hasta un $9 \%$ y $11 \%$ en Nicaragua y El Salvador respectivamente, constituye una medida más cercana a la eficacia de los programas de alfabetización en su objetivo de aumentar los niveles de alfabetismo de la población ${ }^{8}$.

Los casos de Cuba y Chile, que muestran un analfabetismo residual, son excepcionales, aunque en Chile los participantes que terminan el programa representan menos del $2 \%$ de la población analfabeta. En Costa Rica, otro país con bajos niveles de analfabetismo, 4.239 participantes completaron su alfabetización, equivalente a poco más del $3 \%$ de población analfabeta.

Otros países enfrentan mayores desafíos, dada la dimensión de su población analfabeta. Por ejemplo, en Guatemala difícilmente puede reducirse drásticamente el analfabetismo considerando que la población inscrita no llega al 10\% de la totalidad de población analfabeta y el número de participantes que ha completado su programa no es significativo respecto al analfabetismo nacional. El caso de México es peculiar: 115.368 adultos han completado programa de alfabetización, cifra alta pero poco alentadora frente a 5,5 millones de analfabetos registrados como tales.

Si bien las cifras de conclusión de los participantes en los programas de alfabetización constituyen un indicador que permite dimensionar la eficiencia interna de los programas, no proporcionan evidencias acerca del logro efectivo de habilidades en lectura, escritura y de realizar operaciones aritméticas sencillas de sus participantes. Si pensamos que la alfabetización debe ser comprendida como un continuo en el cual se pueden distinguir diferentes niveles de alfabetismo, para que las cifras de superación del analfabetismo sean válidas y confiables se requeriría aplicar evaluaciones capaces de dar cuenta de los aprendizajes logrados.

Relacionado con este tema, los primeros resultados del Programa de Evaluación y Monitoreo de la Alfabetización (LAMP) impulsado por el UIS, publicados en los resúmenes de cuatro países que implementaron esta evaluación, indican que aún en países con tasas de analfabetismo significativamente menores al $10 \%$, existe un elevado porcentaje de personas con muchas limitaciones para manejar los niveles más básicos de interpretación de textos informativos ${ }^{9}$. Estos resultados son consistentes con otros estudios similares implementados con anterioridad, como IALS y $\mathrm{ALL}^{10}$.

8 Los valores del indicador de participantes que concluyeron con éxito programas de alfabetización como proporción de la población analfabeta se presentan en los cuadros estadísticos del Anexo.

9 Los primeros resultados de LAMP se han publicado en los "Literacy Country Summary" disponibles para Jordania, Mongolia, Palestina y Paraguay. Estos resúmenes se encuentran en la sección de alfabetización en el sitio web del UIS, www.uis.unesco.org

10 Para más información sobre estos estudios, ver: 1. Educational Testing Service (2001). The International Adult Literacy Survey (IALS): Understanding what was measured. Princeton: ETS. 2. Statistics Canada (2003). Adult numeracy and its assessment in the ALL survey: A conceptual framework and pilot results. Ottawa: Statistics Canada. 
También vale la pena llamar la atención sobre el menor nivel de calidad de los registros que dan cuenta del número de personas que logran finalizar exitosamente los programas de alfabetización. Esto es evidente al constatar que solo 14 países de los 20 que suministraron información de los programas de alfabetización fueron capaces de proveer este tipo de estadísticas, esenciales para realizar una evaluación de la eficacia de los mismos.

Finalmente, una característica relevante de la oferta de alfabetización es una gran diversidad en cuanto a la extensión de los programas, que varían en un rango entre 3 y 12 meses. Esta variabilidad no sólo es expresiva en la comparación entre países, sino es una característica que también se encuentra al interior de cada país.

Este rasgo de la oferta de programas de alfabetización no es sorprendente; estudios anteriores realizados en la región han mostrado que "los programas denominados de alfabetización tienen alcances y duraciones muy distintas, pudiendo ir desde unos pocos meses e incluso unas pocas semanas, hasta programas de dos, tres y hasta cuatro años de duración, algunos con equivalencia (y certificación) respecto del ciclo primario regular del país. Estas diferencias coexisten dentro de un mismo país e incluso dentro de una misma zona" (Torres, 2003).

En la duración de los programas inciden las campañas masivas de alfabetización basadas, generalmente, en estrategias que buscan una amplia cobertura en un breve período de tiempo. No obstante, habitualmente no hay mediciones respecto a la retención y/o resultados alcanzados en los programas.

Siguiendo los resultados de la encuesta y utilizando un umbral de seis meses de duración, en el Cuadro 2 se agrupa a los países en tres categorías según la duración de los programas: países que implementan programas de corta duración, países que implementan programas de mayor duración y, finalmente, países que combinan ambas modalidades. Las siguientes columnas del cuadro presentan la tasa de alfabetización promedio de estos países y el porcentaje de participación promedio en los programas respecto del total de población analfabeta.

Cuadro 2. Duración de programas de alfabetización, tasas de alfabetización y acceso de la población analfabeta a programas de alfabetización

\begin{tabular}{|l|l|c|c|}
\hline \multicolumn{1}{|c|}{ Duración } & \multicolumn{1}{|c|}{ Países y territorios } & $\begin{array}{c}\text { Tasa de alfabetización } \\
\text { de adultos (\%) }\end{array}$ & $\begin{array}{c}\text { Participantes / Población } \\
\text { analfabeta (\%) }\end{array}$ \\
\hline 6 meses y más & $\begin{array}{l}\text { Chile, Colombia, Costa Rica1, } \\
\text { Jamaica1, México, Paraguay, } \\
\text { Puerto Rico, República } \\
\text { Dominicana, Uruguay }\end{array}$ & 93,5 & 5,2 \\
\hline $\begin{array}{l}\text { Ambos tipos de } \\
\text { programas }\end{array}$ & $\begin{array}{l}\text { Antigua y Barbuda1, Ecuador, El } \\
\text { Salvador, Guatemala, Perú }\end{array}$ & 88,1 & 11,4 \\
\hline Menos de 6 meses & Bolivia, Cuba, Nicaragua & 89,7 & 24,2 \\
\hline
\end{tabular}

Notas: (1) Programas provistos solo por el sector público. Los valores presentados corresponden a promedios no ponderados. La información de tasas de alfabetización y la población analfabeta incluyen los datos más recientes para cada país (actualización de Junio de 2013, año de referencia: 2005-2011). El año de referencia para los datos de participantes es 2010, con excepción de Bolivia (2008) y Chile y Guatemala (2011).

Fuente: Instituto de Estadística de la UNESCO, Centro de datos, mayo de 2013 y Encuesta Regional de Estadísticas de Educación de Adultos 2011. 
Se puede observar una relación inversa entre la extensión de los programas y el porcentaje de participación de la población analfabeta. Esta observación es especialmente relevante para Bolivia y Nicaragua, ya que el caso de Cuba, si bien declara contar con programas de menos de seis meses de duración, el número de participantes en programas de alfabetización es poco significativo dado el alto nivel de alfabetización alcanzado en ese país con tasas de alfabetismo de casi el $100 \%$. Por el contrario, los países que implementan programas de seis meses y más alcanzan en promedio una menor cobertura ${ }^{11}$.

La relación entre tasas de alfabetización, la duración de los programas en cada país y la cobertura alcanzada parece indicar una clara relación entre la dimensión del problema que enfrentan los gobiernos, es decir, la cantidad y proporción de personas analfabetas, y las posibilidades de dar una respuesta rápida a este desafío de política educativa, optando en este caso por modalidades de corta duración que se implementan generalmente en el marco de las conocidas como "campañas de alfabetización".

Otra variable que incide en la extensión de los programas es la existencia de una oferta bilingüe. Países que desarrollan programas bilingües como Ecuador, Guatemala, México, Paraguay y Perú informan que estas modalidades requieren y tienen una mayor duración respecto de los programas en español.

En Ecuador, por ejemplo, el programa de alfabetización en español abarca cinco meses de duración, en tanto, el programa dirigido a la población indígena se extiende por un mes más. Guatemala desarrolla un programa de alfabetización denominado Fase Inicial, con una duración de ocho meses para la variante en español y hasta de once meses para la oferta bilingüe. En México, la alfabetización como educación inicial a población hispanohablante tiene como mínimo cinco meses de duración y la ofrecida en contextos interculturales bilingües doce meses.

Es importante señalar que la mayoría de los programas analizados están referidos a una fase inicial de alfabetización. La alfabetización inicial es solo una puerta de entrada hacia el aprendizaje a lo largo de la vida, pues si la persona inserta en un proceso de alfabetización inicial no continúa avanzando hacia la educación básica, tiene muchas posibilidades de olvidar lo aprendido, por lo que la superación del analfabetismo no es definitiva.

\subsection{Logros educativos de la población joven y adulta en la región}

En los últimos años, se han hecho esfuerzos por incrementar el acceso de los niños y jóvenes a la educación primaria y secundaria. En la región de América Latina y el Caribe, el acceso a educación primaria es muy elevado, registrando en 2011 una tasa neta ajustada de matrícula del $95 \%$, mientras que en educación secundaria se había alcanzado ese año una tasa neta de matrícula del $76 \%$.

Sin embargo, a pesar de estos esfuerzos, la región aún cuenta con un importante grupo de población joven y adulta que, por diversos motivos, no ha podido culminar con éxito los niveles primario y secundario de la educación.

11 Es importante resaltar que algunos países no han sido considerados en este análisis debido a que no han brindado información de la duración de sus programas de alfabetización. Este es el caso de Brasil, por ejemplo, donde la variabilidad en la duración de las ofertas de alfabetización de los distintos estados ha dificultado su categorización. 
El Gráfico 5 presenta los datos de logro educativo de la población de 25 años y más para un conjunto de países de la región. Allí se identifican tres grupos de adultos en función de sus logros educativos. En primer lugar, aquellos que no cuentan con escolaridad o bien no han logrado completar la educación primaria, en segundo lugar quienes han completado el nivel primario como máximo y, finalmente, las personas que han completado la educación secundaria u otro nivel posterior. Los primeros dos grupos forman parte de la población objetivo de los programas estudiados en esta sección.

En general, el Caribe de habla inglesa está a la vanguardia en la región en cuanto al logro educativo de su población, situación que se evidencia en el gráfico en los casos de Islas Caimán y Trinidad y Tobago, países donde el $76 \%$ y $56 \%$ de los adultos respectivamente ha completado al menos la educación secundaria. En América Latina, los mayores niveles de educación de la población adulta se registran en Chile y Perú, con más del $50 \%$ de la población con educación secundaria completa. Le siguen en orden decreciente: Venezuela, Argentina y Cuba.

Gráfico 5. Logro educativo de la población de 25 años y más (\%), países de América Latina y el Caribe, 2003-2011

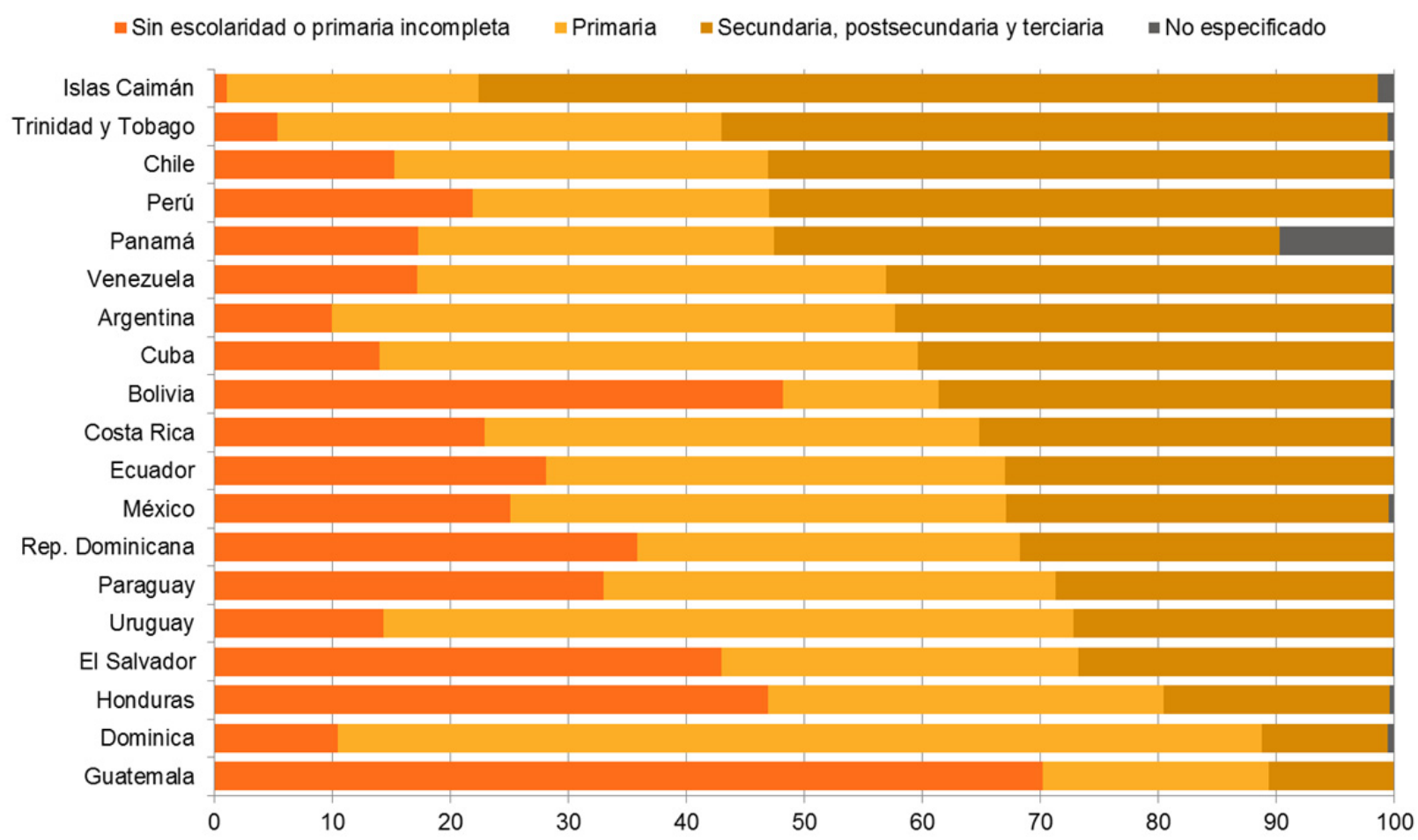

Fuente: Instituto de Estadística de la UNESCO, Centro de datos, mayo de 2013. 
Fuera del grupo de países señalado anteriormente, la población con educación secundaria o superior no supera el $40 \%$ en ninguno de los casos expuestos en el gráfico, lo que da cuenta de la profunda brecha de escolarización existente en el segmento adulto de la población. El escenario de mayor gravedad se registra en Guatemala, donde $70 \%$ de los adultos no tiene escolaridad o bien no ha logrado concluir la educación primaria. En la misma situación se encuentra el $48 \%$ de la población adulta en Bolivia, $47 \%$ en Honduras y $43 \%$ en El Salvador. Si se añade la población que ha concluido la educación primaria pero no ha logrado la titulación de secundaria, a este grupo de países con logros educativos bajos se incorpora Dominica, Uruguay y Paraguay, en los cuales la población adulta que no cuenta con educación secundaria supera el $70 \%$.

Es interesante el caso de Uruguay, que si bien ha logrado niveles de alfabetismo cercanos al $100 \%$ de la población, aún enfrenta un importante desafío en términos de reducir las brechas de escolarización de su población adulta, particularmente en lo referente a la educación secundaria.

\subsection{Participación en educación primaria y secundaria de adultos}

La Encuesta Regional de Estadísticas de Educación de Adultos del UIS fue respondida por 28 países de América Latina y el Caribe, que representan el $98 \%$ de la población regional. Allí se indagaba sobre los programas de educación primaria y secundaria para adultos, equivalentes a los niveles 1, 2 y 3 de la Clasificación Internacional Normalizada de Educación 1997.

Según los datos de esta encuesta, 10.354 .510 adultos se encontraban matriculados en programas de educación primaria (CINE 1) o secundaria (CINE 2 y 3) en el año 2010.

Una primera característica destacable en la conformación regional de estos programas es la clara preponderancia de los programas destinados a la conclusión de la educación secundaria por sobre los dedicados a la educación primaria. Del total de adultos que participaban de estos programas en 2010 , un $73 \%$ está matriculado en la educación secundaria, es decir, tres de cada cuatro estudiantes.

En al menos 15 países, el porcentaje de estudiantes en la educación secundaria supera el 80\%; en el caso de un grupo de países del Caribe anglófono y Belice, sólo se registran estudiantes en este nivel educativo. En el otro extremo, dos países de América Latina, Guatemala y El Salvador, sólo cuentan con estudiantes en la educación primaria de adultos. Estos países habían sido identificados entre los que enfrentan mayores desafíos en términos del logro educativo de la población adulta.

También es interesante dimensionar la relevancia de estos programas dentro de los sistemas educativos nacionales. Para ello, se analiza la participación que tiene la matrícula en educación de adultos dentro de la matrícula total de cada nivel educativo (que incluye, además de la modalidad de adultos, los programas de educación regular). Para la educación primaria, el subsistema de adultos representa el $4 \%$ del total de estudiantes, mientras que en educación secundaria esta proporción alcanza el 12\%. Nuevamente, la educación secundaria de adultos se destaca por su importancia cuantitativa. 
Gráfico 6. Distribución de la matrícula entre educación primaria (CINE 1) y secundaria (CINE 2 y 3) de adultos (\%), países de América Latina y el Caribe, 2010

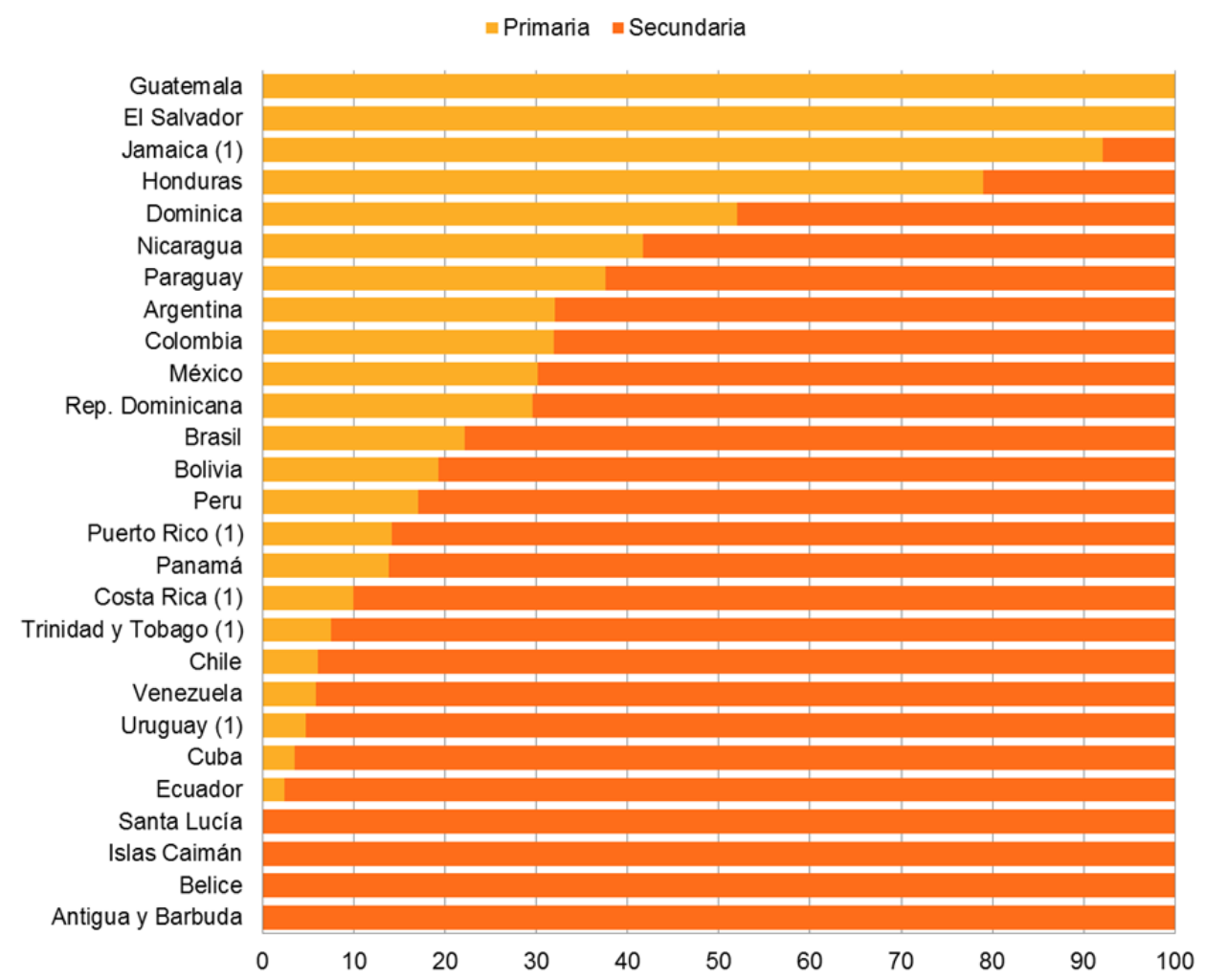

Notas: (1) Programas provistos solo por el sector público. El año de referencia para los datos de matrícula es 2010, con excepción de Bolivia (2009), Chile, Dominica y Guatemala (2011).

Fuente: Instituto de Estadística de la UNESCO y Encuesta Regional de Estadísticas de Educación de Adultos 2011.

Gráfico 7. Participación de la educación de adultos dentro de la matrícula total América Latina y el Caribe, 2010

\section{Primaria}

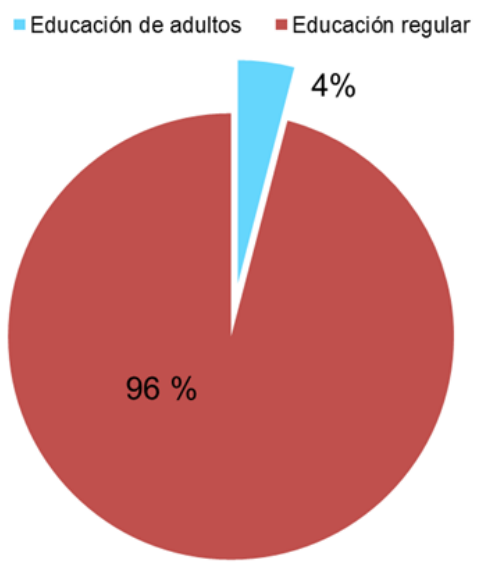

\section{Secundaria}

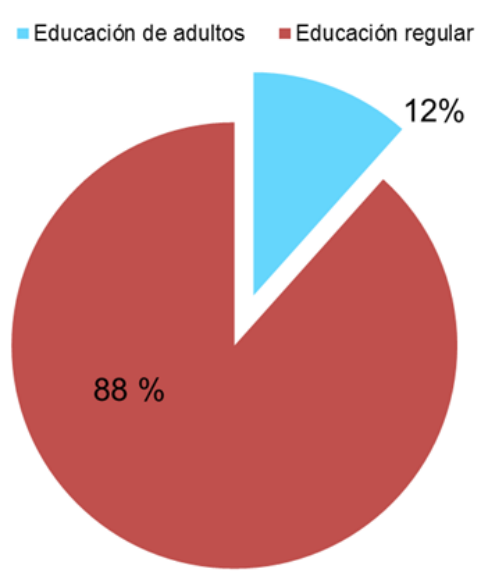

Nota: El año de referencia para los datos de matrícula de educación de adultos es 2010, con excepción de Bolivia (2009) y Chile, Dominica y Guatemala (2011).

Fuente: Instituto de Estadística de la UNESCO, Centro de datos, mayo de 2013 y Encuesta Regional de Estadísticas de Educación de Adultos 2011. 
Estos valores regionales incluyen algunos casos donde la participación de la educación de adultos dentro del sistema educativo es particularmente elevada. En Nicaragua, por ejemplo, los programas de educación de adultos representan el 10\% del total de estudiantes de educación primaria y el $24 \%$ de los estudiantes de secundaria. En Guatemala y Honduras, a su vez, los adultos representan respectivamente el $8 \%$ y $7 \%$ de la matrícula total del nivel primario.

En la educación secundaria, es notable el caso de Cuba, donde la educación de adultos representa el $28 \%$ de la matrícula total del nivel. En este país, la Educación de Jóvenes y Adultos representa un claro subsistema dentro del Sistema Educativo Nacional que comprende educación básica y media superior y que cuenta con docentes formados y una diversidad de propuestas de carácter comunitario y laboral. Un programa altamente inclusivo es el de formación de trabajadores, que brinda oportunidades de desarrollo personal y social.

Con el propósito de poder evaluar la magnitud del acceso de las poblaciones jóvenes y adultas a los programas de educación primaria y secundaria diseñados para este grupo poblacional, se han construido los indicadores que relacionan la matrícula de cada nivel con su correspondiente población objetivo.

De esta manera, la población objetivo en el caso de los programas de educación primaria se definió como aquellos jóvenes y adultos de 15 años y más que no han transitado por el sistema educativo formal o bien, habiendo accedido, no han podido culminar con éxito los estudios primarios. En el caso de los programas de educación secundaria, el grupo objetivo lo constituye la población de 20 años y más sin educación secundaria finalizada.

Considerando estas definiciones, la tasa de matrícula para los programas de educación secundaria de adultos representa un $5,3 \%$. La cobertura de la educación primaria de adultos, en cambio, es bastante menor y alcanza el $2,8 \%$.

Cabe destacar que si bien la matrícula de educación secundaria de adultos triplicaba la de primaria, la diferencia en cobertura medida por estos indicadores no guarda la misma proporción debido a que la población adulta sin educación secundaria es significativamente mayor que aquella que no alcanzó la educación primaria.

El Gráfico 8 presenta la cobertura, en términos de estos indicadores, de los programas de educación primaria (Gráfico 8a) y secundaria (Gráfico 8b) de adultos para los países que disponen de información en ambas dimensiones, es decir, la matrícula de los programas y la población objetivo.

En educación primaria, las mayores coberturas se alcanzan en Honduras $(5,2 \%)$, Colombia $(4,6 \%)$, México $(3,5 \%)$ y Paraguay $(2,9 \%)$. El caso de México es interesante desde lo institucional, ya que el INEA (Instituto Nacional de Educación de Adultos), con varios sexenios de historia, es tal vez la mayor expresión de institucionalidad de la EPJA en la región. Destaca el Programa Modelo de Educación para la Vida y el Trabajo (MEVyT), que no solo incluye competencias para el empleo, sino que se preocupa por la construcción de sujetos sociales, sus aspiraciones y sus condicionantes sociales.

En Paraguay, la EPJA se aboca fundamentalmente a la alfabetización y la educación básica. La educación no formal forma parte del Sistema Educativo Nacional y destaca en la formación en contextos de encierro o cárceles. La influencia de la cooperación internacional ha sido determinante para elevar sustantivamente, vía el Programa PRODEPA, el accionar y la imagen de la EPJA como modalidad importante del sistema educativo nacional a través de múltiples programas. 
Bolivia ocupa el primer lugar en la educación secundaria, alcanzando una cobertura del 13\%. En este país, el Ministerio de Educación respalda una infraestructura considerable de centros de educación de adultos, con edificaciones y maestros capacitados y remunerados. En estos centros se ofrece, a los participantes que obtuvieron buenos resultados en un programa de alfabetización, la oportunidad de continuar aprendiendo, de manera que tras años de estudios provechosos, la mayoría de las veces combinados con formación profesional, logren obtener un certificado de egreso de una escuela superior. La EPJA se incluye en la Educación Alternativa.

\section{Gráfico 8a. Acceso a programas de educación primaria de adultos, países de América} Latina y el Caribe, 2010

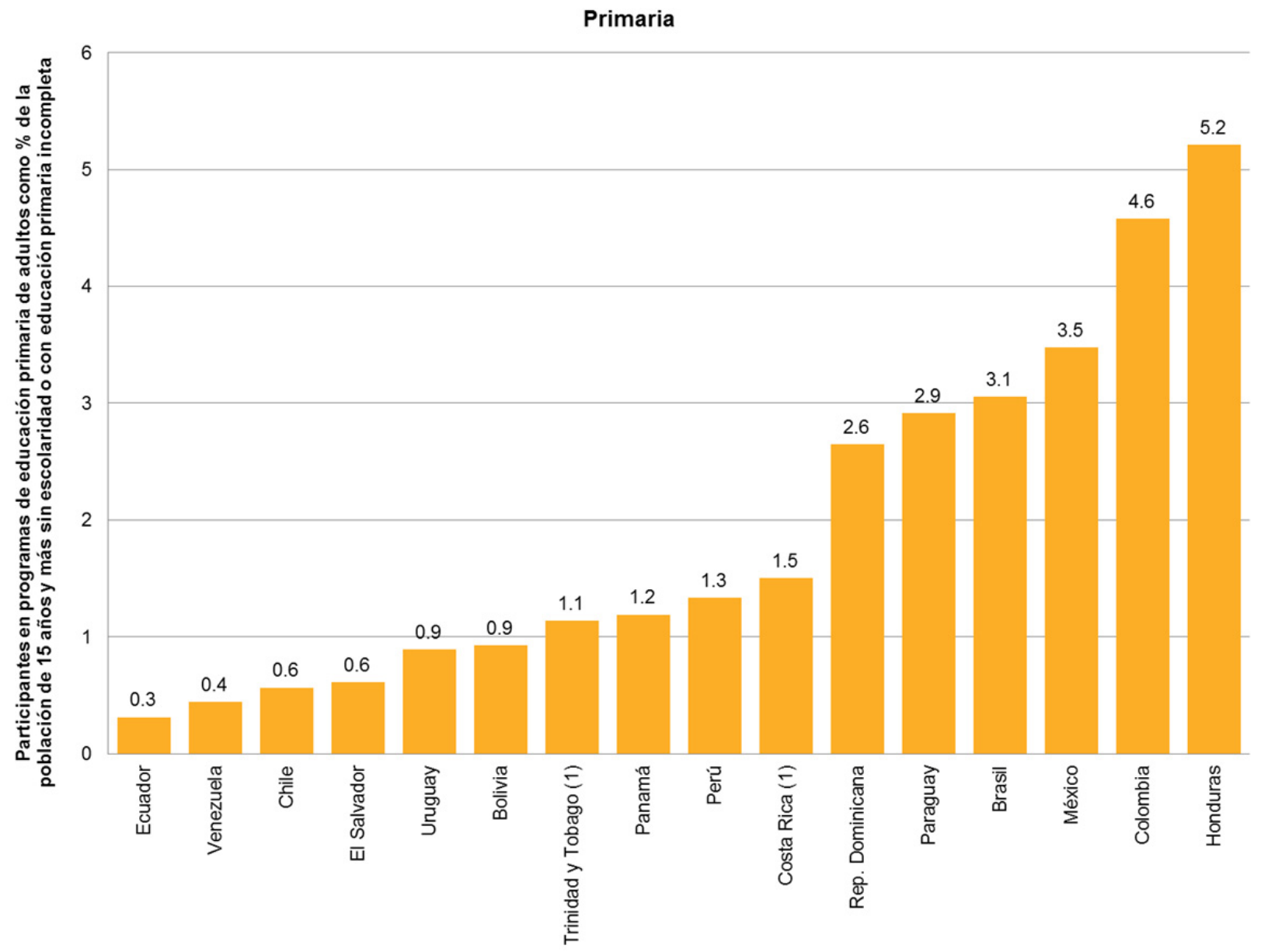

Notas: (1) Programas provistos solo por el sector público. El año de referencia para los datos de matrícula de educación de adultos es 2010, con excepción de Bolivia (2009) y Chile (2011).

Fuente: Instituto de Estadística de la UNESCO, Centro de datos, mayo de 2013 y Encuesta Regional de Estadísticas de Educación de Adultos 2011. 
Gráfico 8b. Acceso a programas de educación secundaria de adultos, países de América Latina y el Caribe, 2010

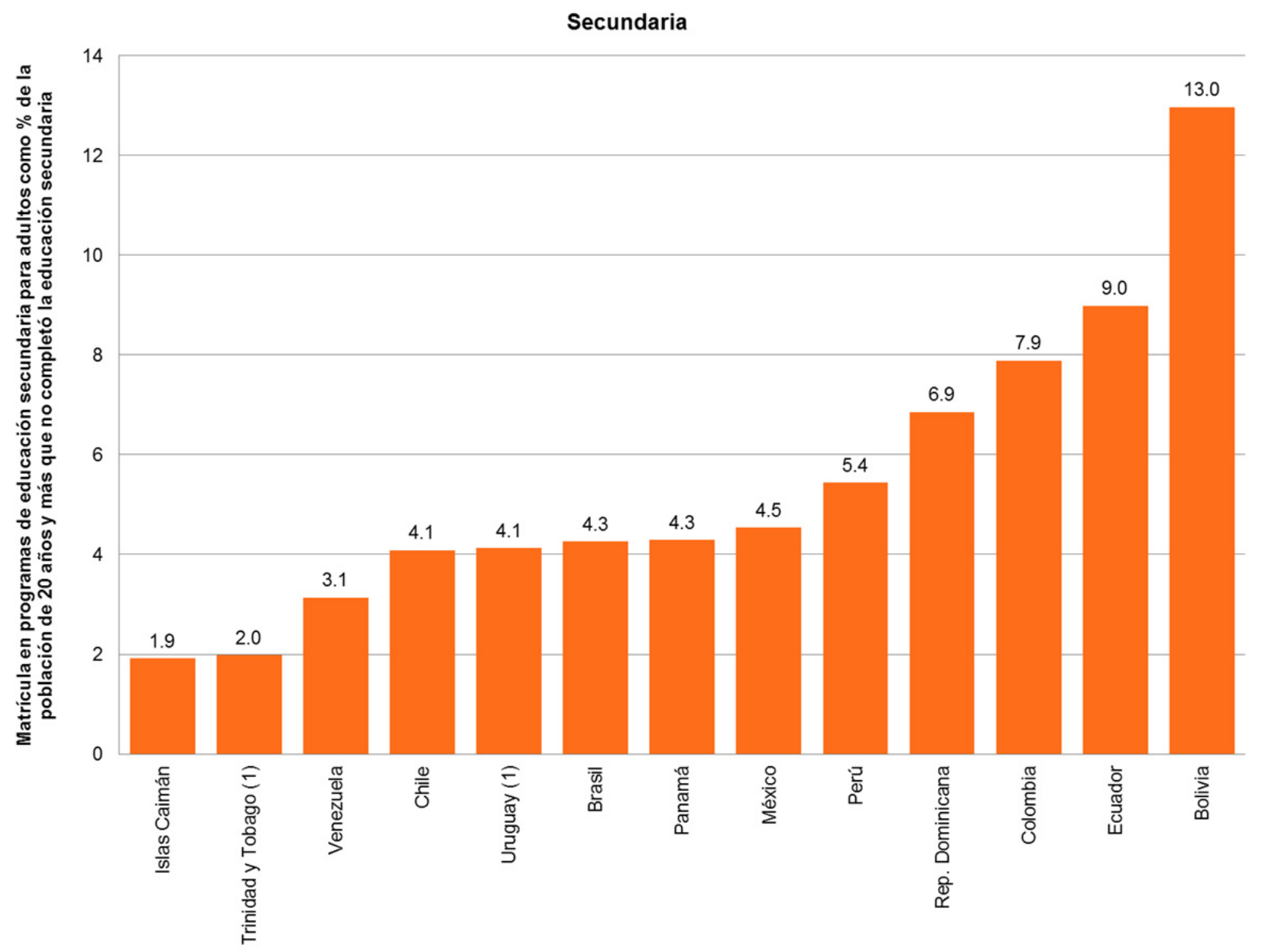

Notas: (1) Programas provistos solo por el sector público. El año de referencia para los datos de matrícula de educación de adultos es 2010, con excepción de Bolivia (2009) y Chile (2011).

Fuente: Instituto de Estadística de la UNESCO, Centro de datos, mayo de 2013 y Encuesta Regional de Estadísticas de Educación de Adultos 2011.

Finalmente, es pertinente analizar quiénes acceden a estos programas de educación, es decir, las características de estos jóvenes y adultos. Para ello, se identifica en primer lugar la distribución por sexo de la matrícula y en segundo lugar, se observa el perfil de edad de los participantes.

La participación de las mujeres es mayor en la educación primaria, representando un 58,4\% de los estudiantes en este nivel, es decir, casi 6 de cada 10. Sin embargo esta diferencia no se mantiene en la educación secundaria, donde se observa prácticamente una paridad entre los sexos, con una proporción de participación levemente a favor de las mujeres, con un 51,4\%. 
Gráfico 9. Porcentaje de matrícula por género en programas de educación de adultos (\%), países de América Latina y el Caribe, 2010

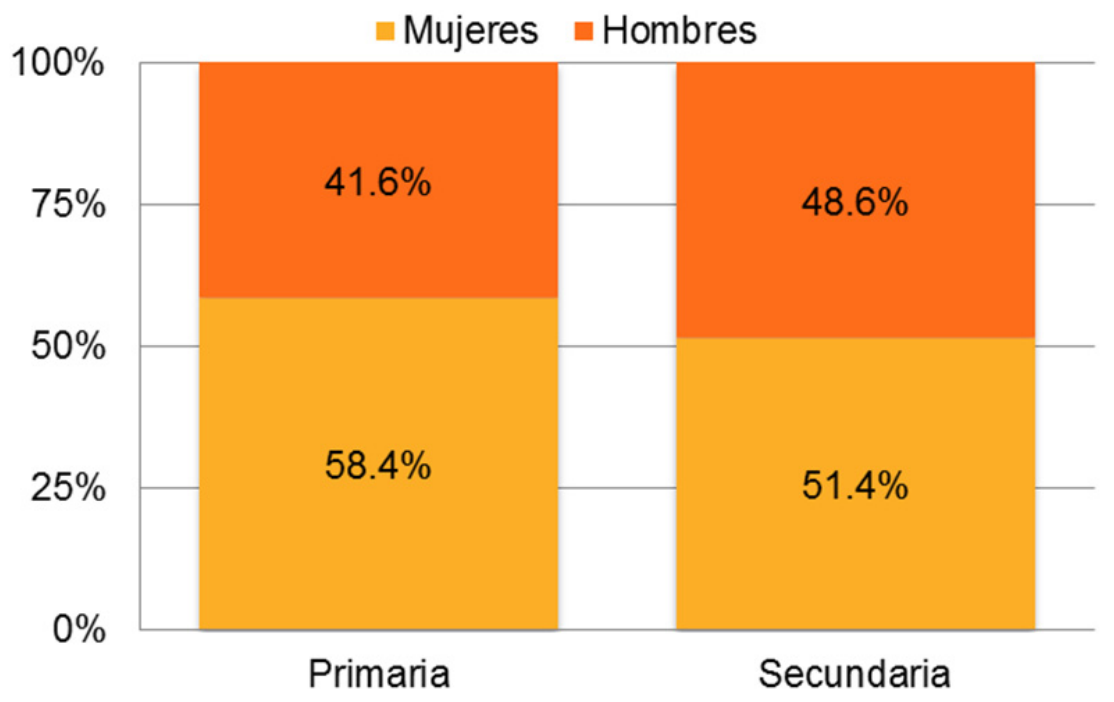

Nota: El año de referencia para los datos de matrícula de educación de adultos es 2010, con excepción de Bolivia (2009) y Chile, Dominica y Guatemala (2011).

Fuente: Instituto de Estadística de la UNESCO y Encuesta Regional de Estadísticas de Educación de Adultos 2011.

Es importante comparar estos resultados con la situación de la población objetivo, para poder diferenciar si la mayor presencia de las mujeres es una característica de los programas o esto refleja la conformación de la población. Se cuenta con esos datos para un conjunto menor de países: 13 de ellos en el caso de la educación primaria y 11 países entre los que aportan datos en secundaria. En estos países, el número de mujeres que no contaba con educación primaria alcanzaba el $54,5 \%$, mientras que las mujeres que no habían completado la educación secundaria representaban el $51,3 \%$ del total.

De los casos países, en el nivel primario se destacan México, Bolivia y Guatemala, con un nivel de participación femenina que supera el $65 \%$ en todos los casos. En el otro extremo, son los varones los que alcanzan una mayor participación en Cuba $(86,8 \%)$, Dominica $(73,6 \%)$, Puerto Rico $(69,5 \%)$, Chile $(67,4 \%)$ y Jamaica $(62,8 \%)$.

En la educación secundaria, aun cuando a nivel regional se registra una paridad entre hombres y mujeres, en los países del Caribe se observa una clara tendencia a una mayor participación de las mujeres, por ejemplo en Jamaica, Islas Caimán, Dominica y Santa Lucia la participación femenina alcanza un 65\%. Entre los países donde los varones lideran la matrícula en programas de educación secundaria, nuevamente se encuentran Puerto Rico $(59,7 \%)$ y Chile (56,7\%), acompañados en este nivel por Perú $(56,9 \%)$.

El análisis de las edades de los participantes en estos programas educativos ratifica la tendencia de una mayor inclusión de jóvenes en programas creados originalmente para atender a la población adulta, fenómeno que se verifica con gran contundencia en la educación secundaria.

En este nivel educativo, los programas en principio destinados a los adultos atraen gran cantidad de jóvenes que incluso se encuentran en muchos casos dentro del rango de edad 
típica asociado a la educación regular de ese nivel. Por lo tanto, se impone una reflexión sobre las causas, al considerar que la alternativa educativa para adultos ha obtenido un lugar importante, debido probablemente a la mayor flexibilidad que permite a jóvenes que han abandonado recientemente los estudios retomar un itinerario educativo y combinar con, por ejemplo, necesidades de ingreso al mercado laboral o atender requerimientos familiares.

El Gráfico 10 presenta el perfil de edad de los participantes por país en programas de educación primaria y secundaria de adultos.

Gráfico 10. Matrícula por grupos de edad en la educación adultos (\%), países de América Latina y el Caribe, 2010
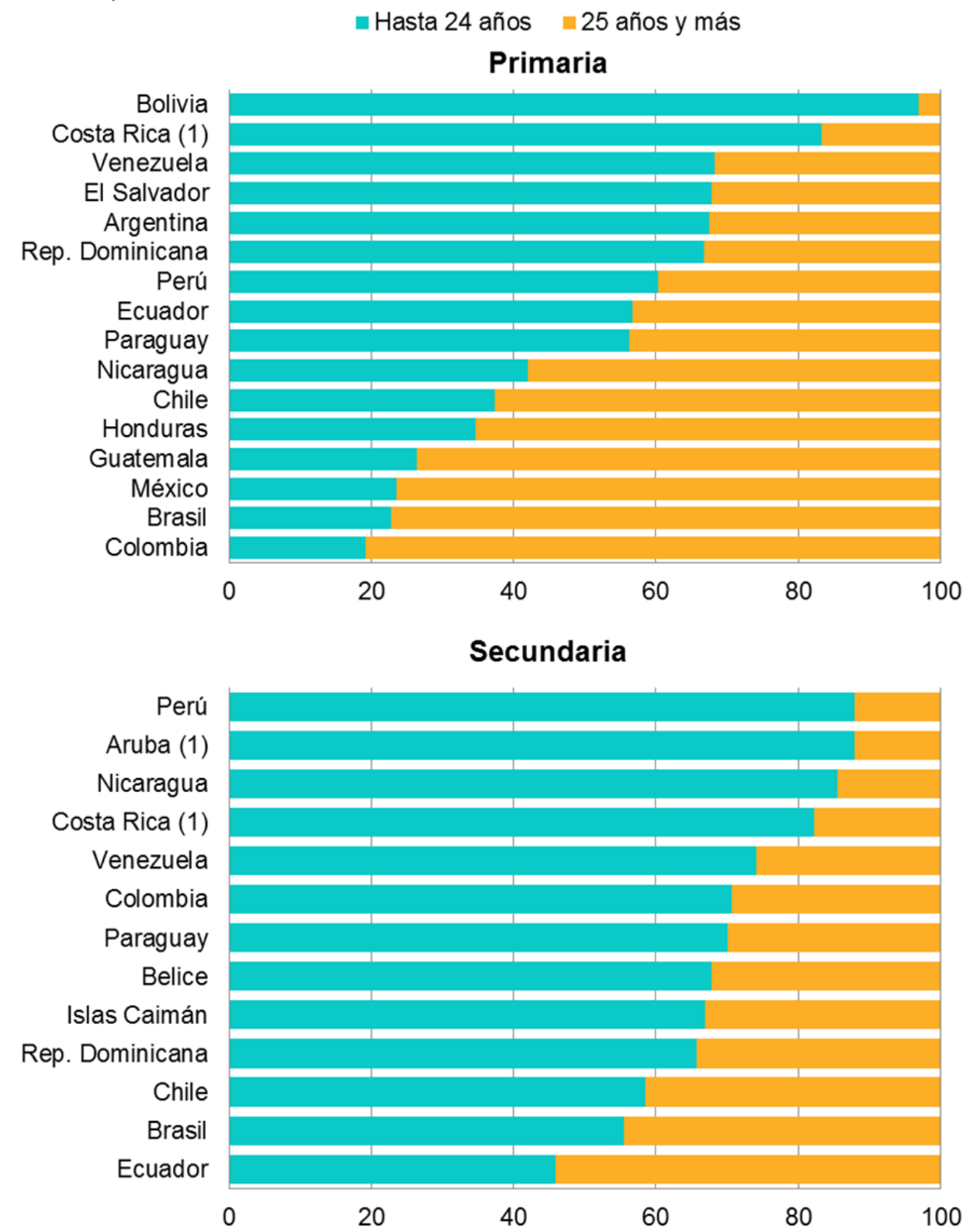

Notas: (1) Programas provistos solo por el sector público. El año de referencia para los datos de matrícula de educación de adultos es 2010, con excepción de Bolivia (2009), y Chile y Guatemala (2011). Fuente: Instituto de Estadística de la UNESCO y Encuesta Regional de Estadísticas de Educación de Adultos 2011. 
Por el lado de la educación primaria, el patrón descrito de preponderancia juvenil en la participación no es tan contundente, aunque en 9 de los 16 países con información disponible más del $50 \%$ de los matriculados en este nivel educativo tienen 24 años o menos. Bolivia representa un caso extremo: más del $90 \%$ de los estudiantes en los programas de educación primaria son jóvenes. Entre los países en los cuales la matrícula de adultos ( 25 años y más) es mayoritaria se destacan tres de los de gran población, como Brasil, México y Colombia. Estos tres países explican dos terceras partes del total de matrícula de educación primaria de adultos de la región.

Tal como ya se hizo notar y a diferencia del nivel primario, en la educación secundaria se identifica una marcada tendencia a la participación mayoritaria de jóvenes. Los estudiantes de hasta 24 años representan más del $60 \%$ en 11 de los 15 países con información disponible. Nuevamente Brasil se encuentra entre los países en los cuales la participación de jóvenes es menor (aunque en este nivel igualmente supera el 50\% de la matrícula). Ecuador es el único país en el que la participación de jóvenes en la educación secundaria de adultos es menor al $50 \%$. 


\section{Conclusiones}

\subsection{Hallazgos del estudio}

Esta primera Encuesta constituye un avance en las deficitarias estadísticas de la educación de personas jóvenes y adultas. Sus resultados confirman una serie de observaciones que deben ser consideradas en las políticas educacionales, y contribuye al seguimiento de los objetivos enunciados en el marco de acción de Belem (CONFINTEA VI).

El estudio evidencia la diversidad de la educación de personas jóvenes y adultas, en cuanto a modalidades de educación (alfabetización, educación primaria y secundaria) y características de los participantes, entre las cuales cabe mencionar las diferencias etarias, de género y de origen étnico.

En relación con los programas de alfabetización, confirma las tendencias observadas respecto de su cobertura y características. En relación a la demanda potencial, la cobertura de los programas es baja. A pesar de los avances en las tasas de alfabetización en América Latina y el Caribe, los datos disponibles señalan que 35,9 millones de personas de 15 años o más son analfabetos: esta es la población de potenciales demandantes de programas de alfabetización de adultos. No obstante, los datos suministrados por los países registran para 2010 un total de 2.529.930 de participantes en los programas de alfabetización; ello representa el 8,3\% de la población analfabeta en esos países. Estos datos indican que la oferta de programas de alfabetización es ampliamente insuficiente en relación con las necesidades de la población.

A su vez, el acceso a los programas no garantiza que los participantes concluyan con éxito su proceso de alfabetización. Como lo muestran los resultados de la encuesta, es habitual que un tercio o más de los participantes se retiren antes de terminar el programa; en algunos casos esta cifra se eleva a un 50\%. Aunque excede a los propósitos del estudio, es necesario señalar que habitualmente los programas no cuentan con sistemas de evaluación de aprendizajes que permitan comprobar el logro alcanzado por los participantes. Este es un desafío pendiente, más aún cuando se entiende que la alfabetización es la puerta de entrada hacia el aprendizaje permanente.

Los programas son de duración variable. A efecto de análisis se agruparon tres tipos de países: los que reportan programas que duran seis meses o menos, los que informan contar con programas de seis o más meses y los que señalan contar con programas de ambas categorías. A su vez, un número importante de países omitió la entrega de información respecto a esta pregunta, pues el grado de variabilidad interna en la duración de los programas no les permitía facilitar información completa.

Del análisis de la información disponible se puede observar que a mayor duración de los programas menor es su cobertura en relación con la población objetivo, y que entre los países que señalan contar con programas de menos de seis meses de duración se encuentran aquellos que tienen mayores tasas de analfabetismo. Probablemente esto último se debe a una necesidad política de contar con una disminución rápida de las tasas de alfabetización, lo que no significa que las personas que participen en este proceso logren desarrollar las competencias requeridas en un nivel aceptable de alfabetismo. 
Igualmente hay que destacar que la duración de los programas también se relaciona con el tipo de población a la cual se dirigen: en las poblaciones indígenas, los programas tienen una mayor extensión. Países como Guatemala, Ecuador, México y Paraguay diferencian entre la duración de programas destinados a la población hispanoparlante de los destinados a las poblaciones indígenas, a las cuales se ofrecen programas de mayor extensión

Otro dato destacable es la participación femenina en los programas, la que alcanza el 65,5\% del total de los participantes en el total de los países que han reportado datos. Este valor es incluso mayor que el porcentaje de mujeres en la población analfabeta de estos países que llega al 55,7\%. Esto indicaría un esfuerzo de intentar cerrar una de las desigualdades existentes, la de género, sobre la que mayor énfasis se ha puesto en los últimos años en las distintas regiones en desarrollo en el mundo.

Respecto de la educación primaria y secundaria de adultos, los datos de la encuesta revelan que 10.354.510 personas jóvenes y adultas se encontraban matriculadas en un programa de esta modalidad en el año 2010. De estos participantes, un 73\% correspondía a la educación secundaria, lo que evidencia la relevancia del nivel secundario dentro del universo de la educación de personas jóvenes y adultas.

Esta diferencia en el volumen de estudiantes por niveles también se pone en evidencia cuando se observa el peso que estos programas tienen en los respectivos niveles educativos respecto de las modalidades regulares. En efecto, en el año 2010, la matrícula en educación primaria de adultos representaba en promedio el $4 \%$ de la matrícula de la educación primaria total para ese nivel educativo, en cambio, la de educación secundaria significaba el $12 \%$ de la matrícula total para el nivel. Sin embargo, vale la pena destacar que en algunos países, como Nicaragua, Guatemala y Honduras, los adultos que cursan la educación primaria representan cerca del $10 \%$ del total de los estudiantes del nivel.

Se puede concluir que en países de más baja escolaridad, que coincide con los que tienen mayor porcentaje de población rural e indígena, hay necesariamente una mayor participación de la población en educación primaria, lo que revela un grave déficit educativo, necesario de considerar en políticas educacionales y de cooperación internacional.

La cobertura que alcanzan los programas de educación de personas jóvenes y adultas en relación a la población objetivo es modesta. En el caso de la educación primaria, aproximadamente $2,8 \%$ de las personas de 15 años y más sin escolaridad o bien con educación primaria incompleta se encontraban asistiendo a un programa de educación primaria. Para el nivel secundario, la cifra se elevaba a 5,3\% respecto de las personas de 20 y más sin educación secundaria completa.

En cuanto al perfil de los participantes, se observa que la participación de mujeres es mayor en la educación primaria $(58,4 \%)$, siendo casi paritaria en educación secundaria, levemente a favor de las mujeres $(51,4 \%)$. Al diferenciar los países, se evidencia la menor escolaridad de las mujeres en los países en los que hay mayor presencia femenina en educación primaria.

En cuanto a edad, el estudio aporta cifras concluyentes que muestran la mayor participación juvenil, especialmente en educación secundaria de personas adultas. Aunque la encuesta no indaga acerca de causas al respecto, se puede señalar que la alternativa de educación de adultos es capaz de ofrecer un tipo de educación más adecuado para jóvenes que han abandonado recientemente los estudios por necesidades de ingreso o atención de problemas familiares. De este modo, los jóvenes hasta 24 años representan más del $60 \%$ en la matrícula de educación secundaria de adultos en 11 de los 15 países con información disponible. 


\subsection{Prioridades para un desarrollo estadístico futuro}

La educación de personas jóvenes y adultas, y más aún en el contexto del aprendizaje a lo largo de la vida, tiene muchas expresiones entre lo que se ha llamado educación no formal y educación popular. Por este motivo, sería conveniente que una encuesta que intente abarcar la riqueza que encierra la EPJA se abriera a considerar e incluir estas ofertas, lo que significaría, además, el desafío de obtener los datos no sólo de los organismos oficiales sino de los muchos sostenedores de programas de la sociedad civil.

En todas las modalidades y programas educativos es necesario evaluar el aprendizaje logrado por los participantes. A diferencia de la educación de niños y jóvenes, en que la mayoría de los países cuentan con sistemas de medición de la calidad y existen experiencias de participación periódicas en pruebas internacionales, como son las desarrolladas por el Laboratorio Latinoamericano de Evaluación de la Calidad de la Educación de UNESCO, PISA o TIMSS, en educación de personas jóvenes y adultas son pocas las instancias de generación de conocimiento a través de intercambio y de participación en este tipo de pruebas y más escasas aún las experiencias de desarrollo de Sistemas de Evaluación y Certificación de Estudios específicos para la educación de personas jóvenes y adultas. Para el futuro será necesario impulsar investigaciones y programas destinados a generar estadísticas comparables acerca de los aprendizajes logrados en programas de alfabetización y educación primaria y secundaria de jóvenes y adultos.

Respecto de la alfabetización, resulta evidente la gran necesidad de que en varios países se puedan reforzar las estructuras que permitan generar estadísticas de alfabetización de calidad en esta materia. Un elemento que evidencia esto es el hecho de que en varios países, a pesar de contar con registros de las personas inscriptas en programas de alfabetización, no cuentan con buena información de las personas que concluyen exitosamente estos programas, información esencial para poder conocer la eficacia de éstos.

Una razón que podría explicar la situación descripta en el párrafo anterior es que, aun en los casos en que estos programas se organizan dentro de los mismos ministerios de educación, casi que no aprovechan para su propio beneficio las estructuras y experiencia que estos ministerios ya tienen para la producción de estadísticas en el área de educación básica. En su lugar, se generan dependencias paralelas que inician sus actividades desde cero y que, además, en la mayoría de los casos, se encuentran asociadas a la sobrevivencia de los programas específicos dentro de los cuales se encuentran.

Muchas veces estos programas se organizan en estructuras institucionales que van por fuera de los ministerios de educación e incluso independientemente del sector público, ya que la iniciativa es tomada por actores privados. Todas estas maneras de afrontar la organización de estos programas son perfectamente válidas, sin embargo plantea desafíos mucho más complejos desde el punto de vista de la factibilidad de poder producir estadísticas consolidadas a nivel de país.

Aunque fuera del alcance de este estudio, un tema insoslayable vinculado a la medición de los niveles de alfabetismo es cómo poder ir más allá de las tasas de analfabetismo, medida tradicional utilizada en esta área y que aborda la cuestión desde una óptica dicotómica. 
En este sentido, pueden destacarse dos tipos de iniciativas. Por un lado, encuestas de hogares en algunos países ya han introducido cambios metodológicos que sustituye la pregunta usual sobre si la persona sabe leer y escribir por un juicio que debe emitir el entrevistador sobre las competencias de alfabetismo del entrevistado a partir de la lectura de un texto breve que este último realiza. En segundo lugar, la implementación de estudios mucho más sofisticas que buscan caracterizar a las personas de acuerdo al nivel de sus competencias en alfabetismo sobre la base de una evaluación realizada en los hogares. Ejemplo de esto es la evaluación LAMP implementada por la UNESCO en 2011 (UNESCO 2009, op. cit.)

Un aspecto importante de considerar es la vinculación de la EPJA con la capacitación laboral. Asumir la continuidad de la formación de jóvenes y adultos en las dimensiones de formación integral y de formación para el trabajo, representa enfrentar dos problemas que se imbrican: qué articular en términos de contenidos y competencias, y cómo acreditar los saberes logrados en diversos ámbitos, formales o no. El concebir la educación de personas jóvenes y adultas en el contexto de aprendizaje a lo largo de la vida exige que ésta responda a los diferentes requerimientos de los diversos aspectos de la vida de los estudiantes, entre los cuales se destaca el aspecto laboral.

Por último, en el contexto de los acelerados cambios tecnológicos del siglo XXI, se plantea como necesario ampliar los conceptos de alfabetización e incluir nuevos códigos relacionados con la virtualidad digital. Las brechas digitales y el "analfabetismo tecnológico" deberán en el futuro estar consideradas en las encuestas que miden el nivel de alfabetismo de la población. La información acerca del acceso y uso de tecnologías permitirá el diseño de políticas destinadas a la formación de la población económicamente activa, al mismo tiempo, que asumir los nuevos códigos lingüísticos y alfabetización digital. 


\section{Bibliografía}

CEAAL (2013) A paso lento. Análisis de los avances en el cumplimiento de la CONFINTEA VI. CEAAL, Grupo de Incidencia en Políticas Públicas (GIPE). Con apoyo de DDV. Lima, junio 2013.

CEPAL (2010) Anuario Estadístico 2010. Santiago, Chile.

CEPAL (2009) Hoja informativa. Objetivos de Desarrollo del Milenio. Santiago, Chile

CEPAL/UNESCO (2009). Impacto social y económico del analfabetismo: modelo de análisis y estudio piloto. Santiago, Chile.

CONALFA (2009). La alfabetización. Una oportunidad para la población excluida. Ciudad de Guatemala.

CREFAL/CEAAL (2008) Situación presente de la educación con personas jóvenes y adultas en América Latina y el Caribe. Informe Regional. Arlés Caruso, María Clara Di Pierro, Mercedes Ruiz y Miriam Camilo. Editorial CREFAL. Pátzcuaro, Mich. México.

DELORS, JACQUES (1996). La educación encierra un tesoro. UNESCO, México.

ECUADOR (2007). Plan decenal de educación del Ecuador 2006 -2015. Rendición de cuentas enerojunio 2007.Ministerio de Educación/Consejo Nacional de Educación, Quito.

ESCOTET, Miguel Ángel. (1992) Aprender para el Futuro (Aprendiendo para el futuro). Madrid. Alianza Editorial.

GUERRERO, Catalina. (2003) Principales aportes de las conferencias internacionales de la educación de adultos de la Unesco al campo de la formación ocupacional. Revista "Education", № 20-21, diciembre 2003. Murcia, España

INFANTE, M. ISABEL (2000). El alfabetismo funcional en siete países de América Latina. UNESCO, Santiago, Chile.

INFANTE, Isabel y LETELIER, M. Eugenia (2013) Alfabetización y Educación. Lecciones de la práctica innovador en América Latina y el Caribe. OREALC Santiago, Chile

LETELIER, María Eugenia (2009) La construcción de un sistema de indicadores en programas de alfabetización y educación permanente. En "Alfabetización y educación básica de jóvenes y adultos". Mariano Jabonero, José Rivero (coordinadores). Metas Educativas 2021. OEl/Fundación Santillana. Madrid

MONTES, Nancy (2010) La información estadística disponible y la necesaria sobre la educación de jóvenes y adultos. Notas metodológicas. En:

OIT, 1998. La Educación permanente en el siglo XXI: nuevas funciones para el personal de la educación. Informe para el debate de la reunión paritaria sobre educación permanente en el siglo XXI: nuevas funciones para el personal de la educación. Ginebra.

PATELI. (2001) Adult literacy. Policy and Practice en la India. (Citado en Chris Duke/Heribert Hinzen. Políticas para la educación básica y permanente de adultos. DVD, 2005)

RIVERO, José (1993). Educación de adultos en América Latina. Desafíos de la equidad y la modernización. Editorial Popular, Madrid.

RIVERO, JOSÉ (2008). Educación y actores sociales frente a la pobreza en América Latina. CLADE CEAAL. Editorial Tarea. Lima.

TORRES, Rosa María (2003). Luego de la alfabetización, ¿la post-alfabetización? Problemas conceptuales y operativos. En: http://www.oei.es/alfabetizacion/Postalfabetizacion.pdf 
TORRES, Rosa María (2009). De la alfabetización al aprendizaje a lo largo de la vida: tendencias, temas y desafíos de la educación con personas jóvenes y adultas en América Latina y el Caribe. UNESCO/IUAL/CONFINTEA VI. México.

UNESCO/CEAAL/CREFAL/INEA (2000) La educación con personas jóvenes y adultas en América Latina y el Caribe: Prioridades de acción en el siglo XXI. Coedición, Santiago, Chile.

UNESCO (1990). Conferencia Internacional de Jomtien. Informe Final. Paris.

UNESCO (1997) CONFINTEA V; Educación de adultos y desarrollo. Bonn.

UNESCO (2000). Alfabetización para Todos - Década de las Naciones Unidas para la Alfabetización (2003- 2012). Documento base UNESCO

UNESCO (2004). La renovación del compromiso con la educación y el aprendizaje de adultos. Informe sobre el Balance Intermedio de CONFINTEA V. Bangkok, Tailandia. Hamburgo.

UNESCO (2004). Pluralidad de la alfabetización, sus implicancias en políticas y programas. Sector Educación de la UNESCO. Documento de orientación. París

UNESCO (2008). Informe Nacional de Jamaica. Jamaican Foundation for Lifelong Learning, Kingston, Jamaica.

UNESCO (2008) PRELAC. Página web: http://www.unesco.org/new/en/santiago/education/education-forall-prelac/prelac/

UNESCO (2010) CONFINTEA VI: VI Conferencia Internacional de Educación de Adultos. Marco de Acción de Belém: aprovechar el poder y el potencial del aprendizaje y la educación de adultos para un futuro viable. Paris.

UNESCO (2009) La nueva generación de estadísticas sobre competencias en alfabetismo: Implementando el Programa de Evaluación y Monitoreo de la Alfabetización (LAMP). Documento técnico $N^{\circ}$ 1. Instituto de Estadística de la UNESCO. Montreal, Quebec, Canadá.

UNESCO (2009) Global Report on Adult Learning on Education (GRALE). UNESCO Institute for Lifelong Learning, Hamburgo.

UNESCO (2011) Panorama regional: América Latina y el Caribe. Informe de seguimiento a EPT en el mundo 2011. París.

UNESCO (2011) Clasificación internacional normalizada de educación (CINE) http://www.uis.unesco.org/Education/Pages/international-standard-classification-of-education.aspx 


\section{Anexo I}

\section{Alcance, estructura y cobertura de la Encuesta Regional de Estadísticas de Educación de Adultos para América Latina y el Caribe}

En agosto de 2011 el Instituto de Estadística de la UNESCO (UIS) envió a los países y territorios de América Latina y el Caribe el Cuestionario Regional de Estadísticas de Educación de Adultos.

El propósito general de la encuesta fue incrementar la disponibilidad de estadísticas en un área específica de la educación de adultos en la que existían muchas debilidades a nivel internacional comparado, pero evaluando que una proporción significativa de países estaban en condiciones de proveer información de buena calidad que permitiera llenar este vació de información.

Esta falta de información ya había motivado el compromiso señalado en el Marco de Acción de Belém por los 144 países participantes de CONFINTEA VI realizada en diciembre de 2009, donde se ratificó la necesidad de "reunir y analizar sistemáticamente datos e información sobre la participación y la evolución de los programas de educación de adultos, desglosados por sexo y otros factores, para evaluar el cambio a lo largo del tiempo y compartir prácticas idóneas" y se instó a la UNESCO y sus estructuras a "apoyar las actividades de seguimiento y supervisión en el plano internacional".

A nivel regional, la importancia de la temática también fue ratificada por los Ministros de Educación de la región reunidos en la II Reunión de la Mesa del Comité Intergubernamental de EPT/PRELAC, realizada el 25 de noviembre de 2010 en Río de Janeiro, Brasil; que apoyó "el desarrollo de un sistema de indicadores sobre alfabetización y educación de adultos, conjugando los esfuerzos de los organismos involucrados como seguimiento directo de la Declaración emanada de la Conferencia Mundial CONFINTEA VI".

La encuesta regional se enfocó en obtener estadísticas de participación y conclusión en tres tipos de programas educativos: alfabetización, educación primaria de adultos (equivalentes al nivel 1 de la CINE 97) y educación secundaria de adultos (equivalentes a los niveles 2 y 3 de la CINE 97). El recuadro que sigue a continuación presenta un resumen de la estructura del cuestionario $^{12}$.

12 El cuestionario, que a su vez contiene las definiciones allí utilizadas, está disponible tanto en inglés como español en el sitio web del UIS, http://www.uis.unesco.org, en la sección "UIS Questionnaires". 


\section{Estructura del Cuestionario Regional de Estadísticas de Educación de Adultos para América Latina y el Caribe}

\section{SECCIÓN 1: INFORMACIÓN GENERAL}

1.1. Período de referencia aplicable a Sección 2 del cuestionario

1.2. Período de referencia aplicable a Sección 3 del cuestionario

1.3. Nombre de los programas de Sección 2 y nivel de acuerdo con la CINE

1.4. Nombre de los programas de Sección 3 y su duración teórica

SECCIÓN 2: PROGRAMAS DE EDUCACIÓN PRIMARIA Y SECUNDARIA DE ADULTOS (SEGÚN NIVEL CINE, ORIENTACIÓN Y SEXO)

2.1. Matrícula por tipo de institución

2.2. Matrícula por edad

2.3. Graduados por tipo de institución

SECCIÓN 3. PROGRAMAS DE ALFABETIZACIÓN DE ADULTOS (SEGÚN TIPO DE CENTRO, DURACIÓN Y SEXO)

1.1. Participantes

1.2. Participantes que han completado el Programa

\section{APÉNDICE}

- $\quad$ Tipo de centro (público o privado)

- $\quad$ Programas de alfabetización bilingüe

- $\quad$ Participantes de programas de alfabetización de adultos

- $\quad$ Participantes que han completado un programa de alfabetización de adultos

La encuesta fue respondida con datos válidos por 30 de los 43 países y territorios de la región de América Latina y el Caribe que representan el $98 \%$ de la población regional ${ }^{13}$.

13 Bermuda y Monserrat respondieron el cuestionario informando que los programas solicitados no son aplicables al sistema educativo nacional. Por este motivo, los países no fueron incluidos en las tablas que figuran en los cuadros estadísticos. 


\section{Anexo II \\ Cuadros Estadísticos}

1. Alfabetización de adultos y jóvenes

2. Logro educativo de la población de 25 años y más

3. Programas de alfabetización para la población adulta

4. Educación primaria de adultos

5. Educación secundaria de adultos

6. Graduados de educación secundaria de adultos

7. Matrícula de educación primaria y secundaria de adultos por edad

En los cuadros estadísticos se emplean los siguientes símbolos:

... No hay datos disponibles

- No se aplica

- $\quad$ Magnitud nula o insignificante

x (c) Datos incluidos en la columna (c) del cuadro

** Estimación del UIS

El año de referencia de los datos de logro educativo

y de la población difiere del año de referencia de la información de matrícula.

(1) Los datos corresponden solo al sector público

(2) Datos parciales 


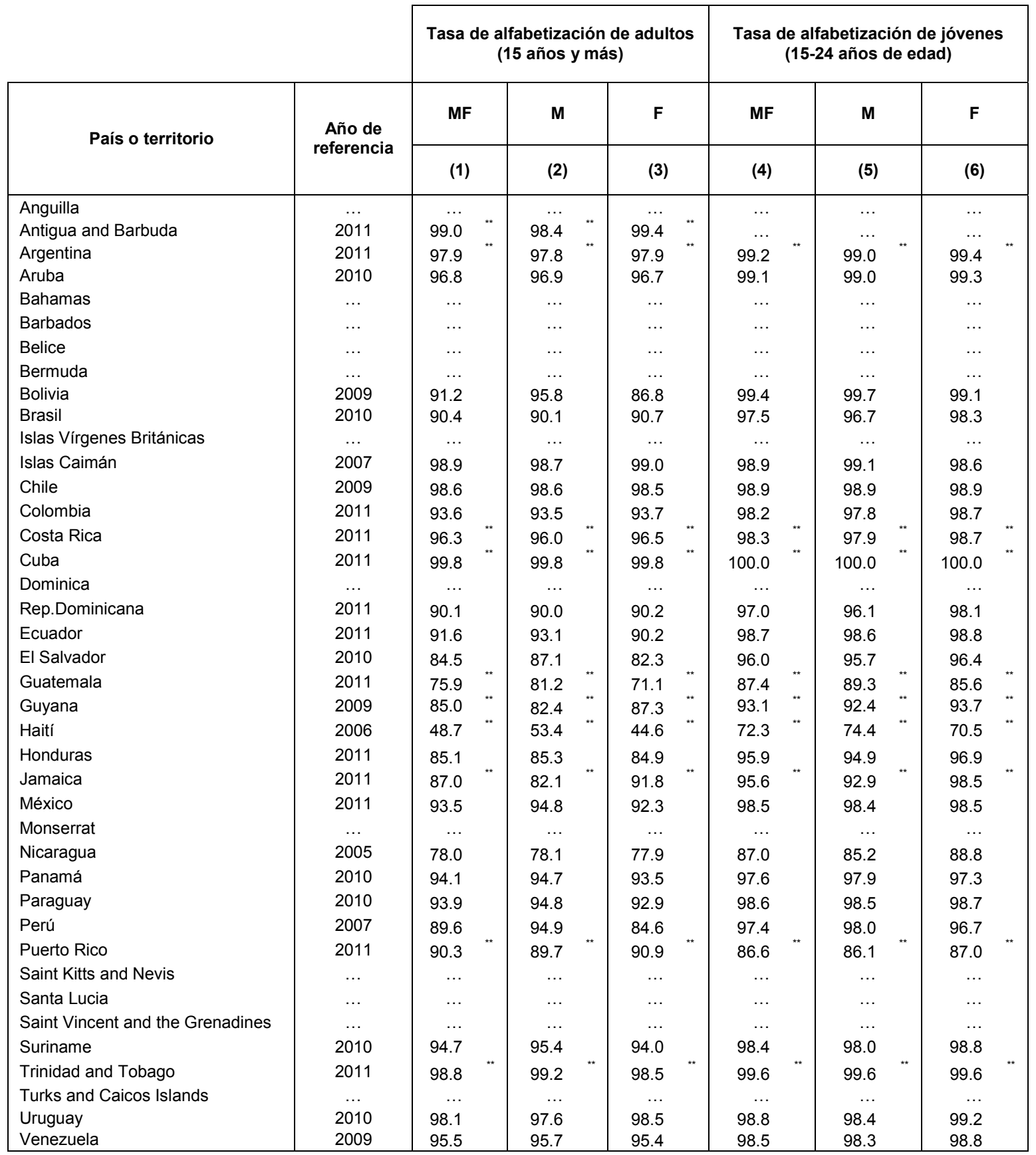


2. Logro educativo de la población de 25 años y más

\begin{tabular}{|c|c|c|c|c|c|c|c|c|c|c|c|c|c|c|c|c|c|c|c|c|c|c|c|c|c|c|c|c|}
\hline \multirow[t]{3}{*}{ Pais o territorio } & \multirow{3}{*}{ 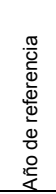 } & \multicolumn{3}{|c|}{$\begin{array}{l}\text { Población (25 años y más) } \\
(000)\end{array}$} & \multicolumn{3}{|c|}{ Sin escolaridad (\%) } & \multicolumn{3}{|c|}{$\begin{array}{l}\text { Educación primaria } \\
\text { incompleta }(\%)\end{array}$} & \multicolumn{3}{|c|}{$\begin{array}{l}\text { Educación primaria } \\
\text { (CINE 1) (\%) }\end{array}$} & \multicolumn{3}{|c|}{$\begin{array}{l}\text { 1er ciclo de } \\
\text { educación } \\
\text { secundaria (CINE 2) } \\
\text { (\%) }\end{array}$} & \multicolumn{3}{|c|}{$\begin{array}{l}\text { 2do ciclo de } \\
\text { educación } \\
\text { secundaria (CINE 3) } \\
\text { (\%) }\end{array}$} & \multicolumn{3}{|c|}{\begin{tabular}{|l} 
Educación \\
postsecundaria no \\
terciaria (CINE 4) (\%)
\end{tabular}} & \multicolumn{3}{|c|}{$\begin{array}{l}\text { Educación terciaria } \\
\text { (CINE 5-6) (\%) }\end{array}$} & \multicolumn{3}{|c|}{$\begin{array}{l}\text { No especificado } \\
(\%)\end{array}$} \\
\hline & & MF & M & $F$ & MF & $M$ & $\mathrm{~F}$ & MF & M & $F$ & MF & $M$ & $F$ & MF & M & $F$ & MF & $M$ & $F$ & MF & $M$ & $F$ & MF & $\mathbf{M}$ & $F$ & MF & M & $\mathbf{F}$ \\
\hline & & (1) & & (3) & (4) & (5) & (6) & (7) & $(8)$ & (9) & $(10)$ & (11) & (12) & (13) & (14) & (15) & (16) & (17) & $(18)$ & (19) & (20) & (21) & (22) & (23) & (24) & $(25)$ & (26) & (27) \\
\hline $\begin{array}{l}\text { Antigu } \\
\text { Barbuc }\end{array}$ & $\cdots$ & & $\cdots$ & 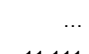 & $\cdots$ & $\cdots$ & $\ldots$ & $\cdots$ &.. &.. & $\ldots$ & $\cdots$ & 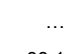 & & $\cdots$ & & $\ldots$ & & & $\cdots$ & $\cdots$ & & & $\cdots$ & & 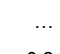 & . & \\
\hline Argentina & 2003 & 21,171 & 10,059 & 11,111 & 1.1 & 0.8 & 1.3 & 8.9 & 8.6 & 9.3 & 33.5 & 33.9 & 33.1 & 14.2 & 16.2 & 12.3 & 28.4 & 28.3 & 28.5 & . & & & \begin{tabular}{|l|l} 
& 13.7 \\
\end{tabular} & 12.0 & 15.3 & 0.2 & 0.2 & 0.2 \\
\hline Aruba & $\ldots$ & $\ldots$ & $\ldots$ & $\cdots$ & $\ldots$ & $\ldots$ & $\ldots$ & $\ldots$ & $\ldots$ & $\ldots$ & $\ldots$ & $\ldots$ & $\ldots$ & $\ldots$ & $\ldots$ & $\ldots$ & $\ldots$ & $\ldots$ & $\cdots$ & $\ldots$ & $\ldots$ & $\ldots$ & $\ldots$ & $\ldots$ & $\cdots$ & $\ldots$ & $\ldots$ & $\ldots$ \\
\hline Belice & $\ldots$ & $\ldots$ & $\ldots$ & $\ldots$ & $\ldots$ & $\ldots$ & $\ldots$ & $\ldots$ & $\ldots$ & $\ldots$ & $\ldots$ & $\ldots$ & $\ldots$ & & $\ldots$ & & $\ldots$ & & $\ldots$ & $\ldots$ & $\ldots$ & $\ldots$ & & $\ldots$ & & $\ldots$ & $\ldots$ & \\
\hline Bolivia & 2009 & 4,253 & 2,063 & 2,190 & 13.5 & 7.1 & 19.4 & 34.7 & 34.9 & 34.5 & 4.7 & 5.2 & 4.3 & 8.5 & 9.9 & 7.2 & 15.6 & 18.1 & 13.4 & - & - & 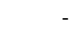 & 22.7 & 24.6 & 21.0 & 0.2 & 0.2 & 0.2 \\
\hline Brasil & 2010 & 111,795 & 53,686 & 58,110 & $x(10)$ & $x(11)$ & $x(12)$ & $x(10)$ & $\mathrm{x}(11)$ & $\mathrm{x}(12)$ & 49.3 & 50.8 & 47.8 & 14.7 & 14.9 & 14.4 & 24.6 & 24.1 & 25.0 & & & & 11.3 & 9.9 & 12.5 & 0.3 & 0.3 & 0.3 \\
\hline Islas Caimán & 2008 & 39 & 19 & 20 & 0.6 & 0.4 & 0.7 & 0.6 & 0.5 & 0.6 & 7.4 & 7.1 & 7.6 & 13.9 & 15.8 & 12.1 & 31.7 & 32.5 & 30.9 & 7.5 & 8.2 & 6.7 & 37.1 & 33.8 & 40.4 & 1.4 & 1.7 & 1.0 \\
\hline Chile & 2010 & 10,378 & 5,037 & 5,341 & 2.9 & 2.7 & 3.2 & 12.3 & 11.7 & 12.9 & 9.6 & 8.9 & 10.3 & 22.1 & 22.8 & 21.5 & 34.7 & 35.4 & 33.9 & & & & 18.0 & 18.2 & 17.9 & 0.4 & 0.4 & 0.4 \\
\hline Colombia & 2011 & 25,086 & 11,970 & 13,116 & 7.9 & 8.0 & 7.8 & $x(10)$ & $x(11)$ & $x(12)$ & 35.7 & 36.3 & 35.2 & 14.5 & 14.1 & 14.7 & 22.1 & 22.3 & 21.9 & . & & & 19.7 & 19.2 & 20.2 & - & - & 0.1 \\
\hline Costa Rica & 2011 & 2,694 & 1,355 & 1,339 & 5.5 & 5.7 & 5.2 & 17.5 & 17.0 & 17.9 & 34.5 & 35.1 & 34.1 & 7.4 & 7.5 & 7.3 & 16.1 & 15.9 & 16.2 & - & - & & 18.8 & 18.4 & 19.2 & 0.2 & 0.3 & 0.2 \\
\hline Cuba & 2002 & 7,336 & 3,650 & 3,686 & 0.2 & 0.2 & 0.2 & 13.8 & 12.4 & 15.2 & 17.2 & 15.6 & 18.7 & 28.4 & 31.2 & 25.7 & 31.0 & 31.4 & 30.6 & - & - & 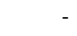 & 9.4 & 9.2 & 9.5 & - & - & - \\
\hline Dominica & 2001 & 38 & 19 & 20 & 3.6 & 3.8 & 3.3 & 6.9 & 7.7 & 6.1 & 62.5 & 65.1 & 60.0 & 15.7 & 12.0 & 19.4 & 5.7 & 5.9 & 5.5 & $x(16)$ & $x(17)$ & $x(18)$ & 5.0 & 5.2 & 4.8 & 0.5 & 0.1 & 0.8 \\
\hline $\begin{array}{l}\text { Rep. } \\
\text { Dominicana }\end{array}$ & 2011 & 5,090 & 2,526 & 2,564 & 10.8 & 10.8 & 10.8 & 25.1 & 25.8 & 24.4 & 10.2 & 10.5 & 10.0 & 22.1 & 23.8 & 20.5 & 21.4 & 20.3 & 22.5 & . & . & & 10.3 & 8.7 & 11.7 & - & - & 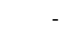 \\
\hline Ecuador & 2010 & 7,369 & 3,634 & 3,735 & 10.6 & 8.8 & 12.3 & 17.5 & 17.5 & 17.5 & 32.1 & 34.3 & 30.1 & 6.8 & 6.5 & 7.1 & 20.6 & 20.9 & 20.4 & 0.8 & 0.7 & 0.8 & 11.6 & 11.3 & 11.8 & . & & \\
\hline El Salvador & 2010 & 2,874 & 1,262 & 1,612 & 4.2 & 3.8 & 4.6 & 38.8 & 35.9 & 41.2 & 15.2 & 15.5 & 15.0 & 15.0 & 16.9 & 13.4 & 19.9 & 20.3 & 19.5 & - & - & - & 6.8 & 7.5 & 6.1 & 0.1 & 0.1 & 0.1 \\
\hline Guatemala & 2006 & 4,825 & 2,240 & 2,585 & 38.9 & 30.8 & 45.5 & 31.3 & 35.0 & 28.4 & 15.0 & 16.8 & 13.5 & 4.2 & 5.2 & 3.3 & 7.2 & 7.5 & 6.9 & & & & 3.4 & 4.7 & 2.4 & - & - & 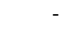 \\
\hline $\begin{array}{l}\text { Honduras } \\
\text { Jamaica }\end{array}$ & 2011 & 3,299 & 1,612 & 1,687 & 18.7 & 18.5 & 18.8 & 28.3 & 29.3 & 27.5 & 25.1 & 24.9 & 25.3 & 8.4 & 8.1 & 8.6 & 11.1 & 10.2 & 11.9 & $\begin{array}{r}2.9 \\
\ldots\end{array}$ & $\begin{array}{r}3.0 \\
\ldots\end{array}$ & 2.9 & 5.1 & 5.4 & 4.9 & 0.4 & 0.6 & 0.2 \\
\hline México & 2010 & 59,643 & 28,829 & 30,813 & 9.3 & 8.0 & 10.5 & 15.8 & 15.5 & 16.1 & 18.3 & 17.6 & 19.0 & 23.7 & 24.5 & 22.9 & 14.8 & 15.1 & 14.6 & . & & & 17.6 & 18.9 & 16.4 & 0.5 & 0.5 & 0.5 \\
\hline Nicaragua & $\ldots$ & & $\cdots$ & &.. & $\ldots$ & $\ldots$ &.. & $\cdots$ & . & $\cdots$ & $\cdots$ & $\ldots$ &.. & $\ldots$ & $\cdots$ & $\cdots$ & & $\therefore$ & $\ldots$ & $\ldots$ & $\ldots$ & $\cdots$ & $\cdots$ &. & $\ldots$ & $\cdots$ & $\ldots$ \\
\hline Panamá & 2010 & 1,889 & 941 & 948 & 7.3 & 6.7 & 8.0 & 9.9 & 10.4 & 9.4 & 21.0 & 22.6 & 19.5 & 9.2 & 9.9 & 8.4 & 20.1 & 20.4 & 19.9 & 1.4 & 1.4 & 1.4 & 21.3 & 18.3 & 24.3 & 9.7 & 10.4 & 9.1 \\
\hline Paraguay & 2008 & 2,807 & 1,407 & 1,400 & 4.5 & 3.3 & 5.6 & 28.5 & 27.4 & 29.5 & 28.2 & 28.4 & 28.0 & 10.2 & 12.0 & 8.4 & 18.2 & 19.7 & 16.7 & & & & 10.4 & 9.1 & 11.7 & & - & 0.1 \\
\hline Perú & 2010 & 14,816 & 7,324 & 7,492 & 6.8 & 2.7 & 10.9 & 15.1 & 12.9 & 17.2 & 18.9 & 19.1 & 18.6 & 6.2 & 6.9 & 5.6 & 32.0 & 36.4 & 27.7 & - & -1 & & 20.9 & 21.8 & 19.9 & 0.1 & 0.1 & 0.1 \\
\hline Puerto Rico & 2008 & 2,364 & 1,094 & 1,270 & $x(13)$ & $x(14)$ & $x(15)$ & $x(13)$ & $x(14)$ & $x(15)$ & $x(13)$ & $x(14)$ & $x(15)$ & 22.3 & 23.4 & 21.3 & 34.9 & 37.9 & 32.3 & 21.6 & 21.1 & 22.2 & 21.2 & 17.6 & 24.2 & & - & \\
\hline Santa L & $\ldots$ & $\cdots$ & $\cdots$ & $\cdots$ & $\ldots$ & $\ldots$ & $\ldots$ & $\ldots$ & $\ldots$ & $\ldots$ & $\ldots$ & $\ldots$ & $\ldots$ & $\cdots$ & $\ldots$ & $\ldots$ & $\ldots$ & $\cdots$ & $\ldots$ & $\ldots$ & $\ldots$ & $\cdots$ & $\cdots$ & $\ldots$ & $\cdots$ & $\ldots$ & $\ldots$ & $\ldots$ \\
\hline $\begin{array}{l}\text { Trinidad and } \\
\text { Tobago }\end{array}$ & 2009 & 810 & 382 & 429 & 1.3 & 0.7 & 1.9 & 4.0 & 3.1 & 4.9 & 34.8 & 36.3 & 33.3 & 2.9 & 2.7 & 3.1 & 12.7 & 10.9 & 14.5 & 34.1 & 36.7 & 31.6 & 9.6 & 8.9 & 10.2 & 0.5 & 0.5 & 0.5 \\
\hline Uruguay & 10 & 2,095 & 976 & 1,118 & 1.6 & 1.4 & 1.8 & 12.7 & 13.1 & 12.5 & 36.1 & 37.3 & 35.2 & 22.3 & 24.0 & 20.9 & 12.5 & 11.5 & 13.3 & 5.3 & 5.3 & 5.3 & 9.4 & 7.4 & 11.2 & - & - & - \\
\hline Venezuela & 2009 & 14,647 & 244 & 403 & 6.6 & 6.5 & 6.8 & 10.6 & 11.6 & 9.6 & 28.9 & 30.9 & 27.0 & 10.8 & 11.5 & 10.1 & 27.0 & 26.0 & 28.0 & & & & 15.9 & 13.3 & 18.4 & 0.2 & 0.2 & 0.1 \\
\hline
\end{tabular}




\section{Programas de alfabetización para la población adulta}

\begin{tabular}{|c|c|c|c|c|c|c|c|c|c|c|c|}
\hline & \multicolumn{2}{|c|}{$\begin{array}{l}\text { Participantes en } \\
\text { programas de } \\
\text { alfabetización }\end{array}$} & \multicolumn{2}{|c|}{$\begin{array}{c}\text { Participantes que han } \\
\text { completado un programa de } \\
\text { alfabetización }\end{array}$} & \multicolumn{3}{|c|}{$\begin{array}{l}\text { Participantes en programas de } \\
\text { alfabetización como porcentaje de } \\
\text { la población analfabeta }\end{array}$} & \multicolumn{3}{|c|}{$\begin{array}{c}\text { Participantes que han completado } \\
\text { un programa de alfabetización como } \\
\text { porcentaje de la población } \\
\text { analfabeta }\end{array}$} \\
\hline & & MF & $\mathbf{F}$ & MF & $\mathbf{F}$ & MF & $M$ & $\mathbf{F}$ & MF & $M$ & $\mathbf{F}$ \\
\hline País o territorio & \begin{tabular}{|c|}
$\begin{array}{c}\text { Año de } \\
\text { referencia }\end{array}$ \\
\end{tabular} & (1) & (2) & (3) & (4) & (5) & (6) & (7) & (5) & (6) & (7) \\
\hline Antigua and Barbuda (1) & 2010 & 31 & 30 & $\ldots$ & $\ldots$ & $4.41^{y}$ & $0.20^{y}$ & $14.76^{y}$ & $\ldots$ & $\ldots$ & $\ldots$ \\
\hline Argentina & $\ldots$ & $\ldots$ & $\ldots$ & $\ldots$ & $\ldots$ & $\ldots$ & $\ldots$ & $\ldots$ & $\ldots$ & $\ldots$ & $\ldots$ \\
\hline Aruba & $\ldots$ & $\ldots$ & $\ldots$ & $\ldots$ & $\ldots$ & $\ldots$ & $\ldots$ & $\ldots$ & $\ldots$ & $\ldots$ & $\ldots$ \\
\hline Belice & 2010 & $\ldots$ & $\ldots$ & $\ldots$ & $\ldots$ & $\ldots$ & $\ldots$ & $\ldots$ & $\ldots$ & $\ldots$ & $\ldots$ \\
\hline Bolivia (Estado Plurinacional de) & 2008 & 296,697 & 207,688 & $\ldots$ & $\ldots$ & 53.37 & 59.24 & 51.19 & $\ldots$ & $\ldots$ & $\ldots$ \\
\hline Brasil & 2009 & 535,054 & 316,220 & $\ldots$ & $\ldots$ & 3.85 & 3.20 & 4.48 & $\ldots$ & $\ldots$ & $\ldots$ \\
\hline Islas Caimán & 2010 & - & - & - & - & - & - & - & - & - & - \\
\hline Chile & 2011 & 6,543 & $\ldots$ & 2,895 & 1,655 & $3.43^{y}$ & $\ldots$ & $\ldots$ & $1.52^{y}$ & $1.38 \mathrm{y}$ & $1.64 \mathrm{y}$ \\
\hline Colombia & 2010 & 323,724 & 196,606 & $\ldots$ & $\ldots$ & 14.81 & 11.78 & 17.75 & $\ldots$ & $\ldots$ & $\ldots$ \\
\hline Costa Rica (1) & 2010 & 7,514 & 4,295 & 4,239 & 2,434 & $5.62^{y}$ & $4.50^{y}$ & $6.91^{y}$ & $3.17^{y}$ & $2.52^{y}$ & $3.91^{y}$ \\
\hline Cuba & 2010 & 559 & 93 & 552 & 93 & $3.61^{y}$ & $6.29^{y}$ & $1.15^{y}$ & $3.56^{y}$ & $6.19^{y}$ & $1.15^{y}$ \\
\hline Dominica & 2011 & $\ldots$ & $\ldots$ & 6 & 5 & $\ldots$ & $\ldots$ & $\ldots$ & $\ldots$ & $\ldots$ & $\ldots$ \\
\hline República Dominicana & 2010 & 60,996 & $\ldots$ & 42,594 & $x(3)$ & 8.51 & $\ldots$ & $\ldots$ & 5.95 & $\ldots$ & $\ldots$ \\
\hline Ecuador & 2010 & 96,920 & 65,451 & 4,890 & 3,162 & 11.85 & 9.40 & 13.55 & 0.60 & 0.52 & 0.65 \\
\hline El Salvador & 2010 & 110,123 & 64,379 & 71,803 & 39,675 & 16.87 & 18.37 & 15.95 & 11.00 & 12.90 & 9.83 \\
\hline Guatemala & 2011 & 148,665 & 125,499 & 83,628 & 70,610 & 7.09 & 2.99 & 9.49 & 3.99 & 1.68 & 5.34 \\
\hline Honduras & 2010 & $\ldots$ & $\ldots$ & $\ldots$ & $\ldots$ & $\ldots$ & $\ldots$ & $\ldots$ & $\ldots$ & $\ldots$ & $\ldots$ \\
\hline Jamaica (1) & 2010 & 6,712 & 2,737 & $\ldots$ & $\ldots$ & $2.64^{y}$ & $2.32^{y}$ & $3.30^{y}$ & $\ldots$ & $\ldots$ & $\ldots$ \\
\hline México & 2010 & 603,035 & 443,318 & 115,368 & 85,314 & 10.84 & 7.27 & 13.18 & 2.07 & 1.37 & 2.54 \\
\hline Nicaragua & 2010 & 116,380 & 62,110 & 68,940 & 43,357 & $15.66^{y}$ & $15.01^{y}$ & $16.28^{y}$ & $9.28^{y}$ & $7.08^{y}$ & $11.37^{y}$ \\
\hline Panamá & $\ldots$ & $\ldots$ & $\ldots$ & $\ldots$ & $\ldots$ & $\ldots$ & $\ldots$ & $\ldots$ & $\ldots$ & $\ldots$ & $\ldots$ \\
\hline Paraguay & 2010 & 10,238 & 7,471 & $\ldots$ & $\ldots$ & 3.90 & 2.48 & 4.95 & $\ldots$ & $\ldots$ & $\ldots$ \\
\hline Perú & 2010 & 204,585 & 161,701 & 133,331 & 105,702 & $10.28^{y}$ & $8.64^{y}$ & $10.82^{y}$ & $6.70^{y}$ & $5.57^{y}$ & $7.07^{y}$ \\
\hline Puerto Rico (1) & 2010 & 343 & 164 & 59 & $x(3)$ & $0.12^{y}$ & $0.12^{y}$ & $0.12^{y}$ & $0.02^{y}$ & $\ldots$ & $\ldots$ \\
\hline Santa Lucia & 2010 & 327 & 253 & . & . & $\ldots$ & $\ldots$ & $\ldots$ & . & . & . \\
\hline Trinidad and Tobago & $\ldots$ & $\ldots$ & $\ldots$ & $\ldots$ & $\ldots$ & $\ldots$ & $\ldots$ & $\ldots$ & $\ldots$ & $\ldots$ & $\ldots$ \\
\hline Uruguay & 2010 & 1,484 & $x(1)$ & $\ldots$ & $\ldots$ & 2.95 & $\ldots$ & $\ldots$ & $\ldots$ & $\ldots$ & $\ldots$ \\
\hline Venezuela (República Bolivariana de) & $\ldots$ & $\ldots$ & $\ldots$ & $\ldots$ & $\ldots$ & $\ldots$ & $\ldots$ & $\ldots$ & $\ldots$ & $\ldots$ & $\ldots$ \\
\hline
\end{tabular}




\section{Educación primaria de adultos}

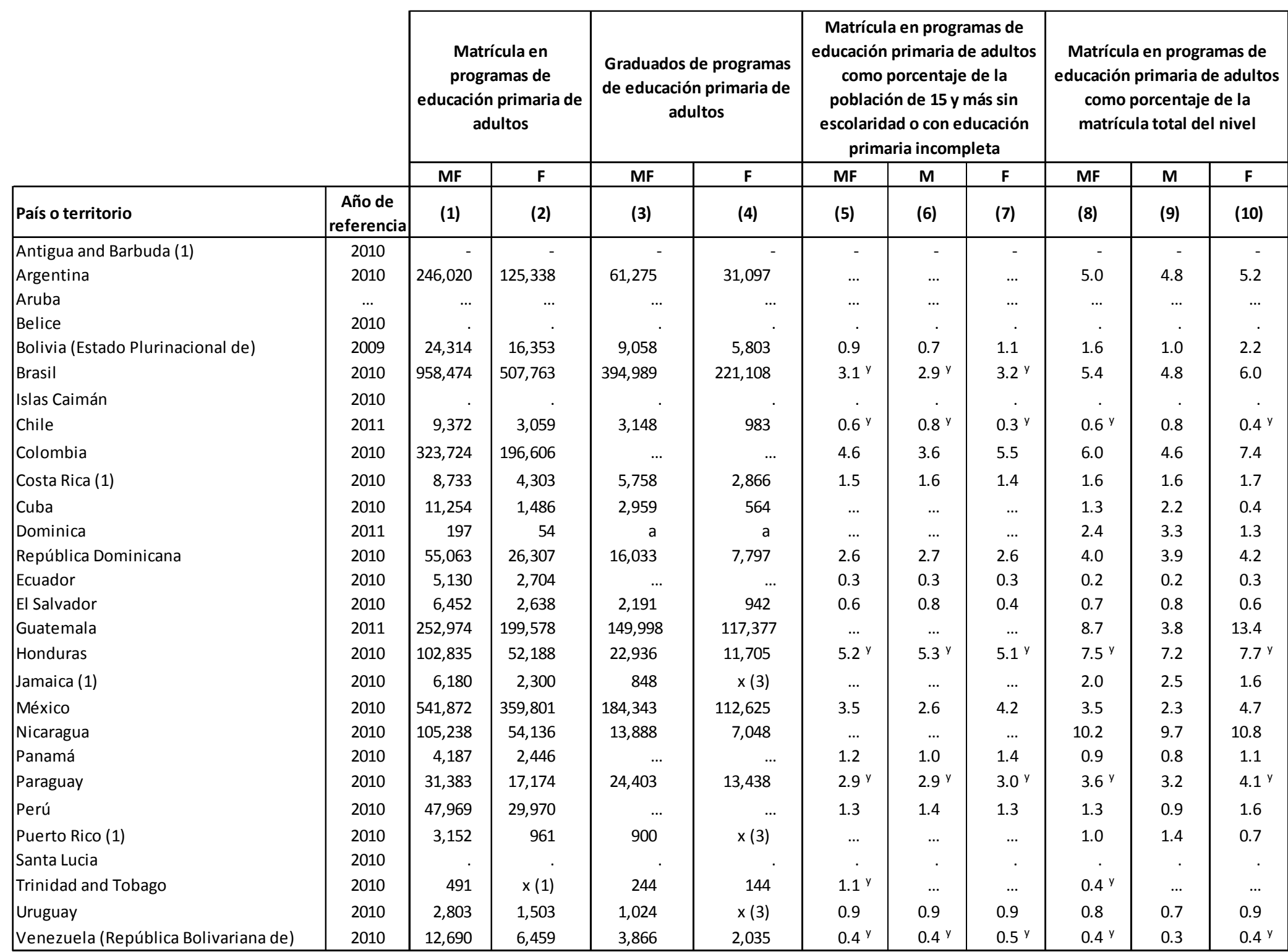




\begin{tabular}{|c|c|c|c|c|c|c|c|c|c|c|c|c|c|}
\hline \multirow[b]{3}{*}{ País o territorio } & \multirow{3}{*}{$\begin{array}{l}\text { Año de } \\
\text { referencia }\end{array}$} & \multicolumn{2}{|c|}{$\begin{array}{l}\text { Matrícula en el primer ciclo } \\
\text { de la educación secundaria }\end{array}$} & \multicolumn{2}{|c|}{$\begin{array}{c}\text { Matrícula en el segundo } \\
\text { ciclo de la educación } \\
\text { secundaria }\end{array}$} & \multicolumn{2}{|c|}{$\begin{array}{l}\text { Matrícula en educación } \\
\text { secundaria }\end{array}$} & \multicolumn{3}{|c|}{$\begin{array}{l}\text { Matrícula en programas de educación } \\
\text { secundaria de adultos como } \\
\text { porcentaje de la población de } 20 \text { años } \\
\text { y más con educación primaria o } \\
\text { secundaria incompleta }\end{array}$} & \multicolumn{3}{|c|}{$\begin{array}{c}\text { Matrícula en programas de educación } \\
\text { secundaria de adultos como } \\
\text { porcentaje de la matrícula total del } \\
\text { nivel }\end{array}$} \\
\hline & & MF & $\mathbf{F}$ & MF & $\mathbf{F}$ & MF & $\mathbf{F}$ & MF & $M$ & $\mathbf{F}$ & MF & $M$ & $\mathbf{F}$ \\
\hline & & (1) & (2) & (3) & (4) & (5) & (6) & (7) & (8) & (9) & (10) & (11) & (12) \\
\hline Antigua and Barbuda (1) & 2010 & 290 & 101 & 758 & 511 & 1,048 & 612 & ... & $\ldots$ & $\ldots$ & 11.1 & 9.6 & 12.4 \\
\hline Argentina & 2010 & $x(5)$ & $x(6)$ & $x(5)$ & $x(6)$ & 522,289 & 269,800 & $\ldots$ & $\ldots$ & $\ldots$ & 12.4 & 12.4 & 12.3 \\
\hline Aruba & 2010 & $\ldots$ & $\ldots$ & 1,201 & 757 & 1,201 & 757 & $\ldots$ & $\ldots$ & $\ldots$ & 14.1 & 10.8 & 17.0 \\
\hline Belice (2) & 2010 & 219 & 150 & 211 & 116 & 430 & 266 & $\ldots$ & $\ldots$ & $\ldots$ & 1.3 & 1.0 & 1.5 \\
\hline Bolivia (Estado Plurinacional de) & 2009 & 21,883 & 11,652 & 80,191 & 38,178 & 102,074 & 49,830 & 13.0 & 12.4 & 13.7 & 8.8 & 8.8 & 8.8 \\
\hline Brasil & 2010 & $1,939,732$ & 925,639 & $1,427,381$ & 762,033 & $3,367,113$ & $1,687,672$ & 4.3 & 4.3 & 4.3 & 12.5 & 12.8 & 12.2 \\
\hline Islas Caimán & 2010 & & & 172 & 126 & 172 & 126 & $1.9^{y}$ & $1.0^{y}$ & $3.0^{y}$ & $5.0^{y}$ & 2.7 & $7.4^{y}$ \\
\hline Chile & 2011 & 15,266 & 5,487 & 129,423 & 57,200 & 144,689 & 62,687 & $4.1 \mathrm{y}$ & $4.7^{y}$ & $3.5^{y}$ & $8.8 \mathrm{y}$ & 9.9 & $7.8^{y}$ \\
\hline Colombia & 2010 & 444,226 & 245,629 & 246,753 & 134,211 & 690,979 & 379,840 & 7.9 & 7.4 & 8.3 & 12.0 & 11.2 & 12.7 \\
\hline Costa Rica (1) & 2010 & 51,845 & 24,232 & 27,136 & 14,617 & 78,981 & 38,849 & $\ldots$ & $\ldots$ & $\ldots$ & 16.0 & 16.2 & 15.8 \\
\hline Cuba & 2010 & 12,487 & 4,235 & 298,588 & 144,602 & 311,075 & 148,837 & $\ldots$ & $\ldots$ & $\ldots$ & 27.8 & 28.0 & 27.6 \\
\hline Dominica & 2011 & 58 & 53 & 124 & 76 & 182 & 129 & $\ldots$ & $\ldots$ & $\ldots$ & 2.7 & 1.6 & 3.8 \\
\hline República Dominicana & 2010 & 43,270 & 21,714 & 87,910 & 51,680 & 131,180 & 73,394 & 6.9 & 5.7 & 8.1 & 12.7 & 11.8 & 13.4 \\
\hline Ecuador & 2010 & 126,742 & 72,862 & 84,524 & 42,236 & 211,266 & 115,098 & 9.0 & 8.2 & 9.7 & 12.5 & 11.4 & 13.6 \\
\hline El Salvador & 2010 & . & . & . & . & . & & . & . & . & . & . & . \\
\hline Guatemala & 2011 & . & . & . & . & & & . & . & . & . & . & . \\
\hline Honduras & 2010 & 27,398 & 14,727 & . & . & 27,398 & 14,727 & $\ldots$ & $\ldots$ & $\ldots$ & 4.0 & 4.1 & 4.0 \\
\hline Jamaica (1) & 2010 & $x(5)$ & $x(6)$ & $x(5)$ & $x(6)$ & 532 & 437 & $\ldots$ & $\ldots$ & $\ldots$ & 0.2 & 0.1 & 0.3 \\
\hline México & 2010 & $1,257,088$ & 699,544 & & . & $1,257,088$ & 699,544 & $4.5^{y}$ & $4.3^{y}$ & $4.7^{y}$ & $9.7 \mathrm{y}$ & 8.9 & $10.5^{y}$ \\
\hline Nicaragua & 2010 & 96,145 & 47,487 & 51,359 & 28,348 & 147,504 & 75,835 & $\ldots$ & $\ldots$ & $\ldots$ & 24.1 & 24.2 & 24.0 \\
\hline Panamá & 2010 & 11,657 & 5,034 & 14,423 & 7,512 & 26,080 & 12,546 & 4.3 & 4.1 & 4.5 & 8.4 & 8.8 & 8.0 \\
\hline Paraguay & 2010 & 15,716 & 8,245 & 36,484 & 19,513 & 52,200 & 27,758 & $\ldots$ & $\ldots$ & $\ldots$ & 8.5 & 8.1 & 8.9 \\
\hline Perú & 2010 & 204,648 & 87,891 & 27,935 & 12,364 & 232,583 & 100,255 & 5.4 & 6.0 & 4.8 & 8.1 & 8.9 & 7.2 \\
\hline Puerto Rico (1) & 2010 & 7,988 & 3,206 & 11,119 & 4,501 & 19,107 & 7,707 & $\ldots$ & $\ldots$ & $\ldots$ & 6.2 & 7.3 & 5.0 \\
\hline Santa Lucia & 2010 & 284 & 187 & 536 & 368 & 820 & 555 & $\ldots$ & $\ldots$ & $\ldots$ & 4.9 & 3.2 & 6.6 \\
\hline Trinidad and Tobago (1) & 2010 & $x(5)$ & $x(6)$ & $x(5)$ & $x(6)$ & 6,031 & $x(5)$ & $2.0^{y}$ & $\ldots$ & $\ldots$ & $6.0 \mathrm{y}$ & $\ldots$ & $\ldots$ \\
\hline Uruguay (1) & 2010 & 13,493 & $x(1)$ & 42,973 & $x(3)$ & 56,466 & $x(5)$ & 4.1 & $\ldots$ & $\ldots$ & 16.4 & $\ldots$ & $\ldots$ \\
\hline Venezuela (República Bolivariana de) & 2010 & 105,305 & 51,031 & 100,640 & 52,265 & 205,945 & 103,296 & $3.1 \mathrm{y}$ & $2.9^{y}$ & $3.4^{\mathrm{y}}$ & $8.4^{\mathrm{y}}$ & 8.5 & $8.2^{y}$ \\
\hline
\end{tabular}




\begin{tabular}{|c|c|c|c|c|c|}
\hline \multirow[b]{3}{*}{ País o territorio } & \multirow{3}{*}{$\begin{array}{l}\text { Año de } \\
\text { referencia }\end{array}$} & \multicolumn{2}{|c|}{$\begin{array}{l}\text { Graduados de primer ciclo de } \\
\text { educación secundaria }\end{array}$} & \multicolumn{2}{|c|}{$\begin{array}{l}\text { Graduados de segundo ciclo } \\
\text { de educación secundaria }\end{array}$} \\
\hline & & MF & $\mathbf{F}$ & MF & $\mathbf{F}$ \\
\hline & & (1) & (2) & (3) & (4) \\
\hline Antigua and Barbuda (1) & 2010 & $\ldots$ & $\ldots$ & $\ldots$ & $\ldots$ \\
\hline Argentina & 2010 & $x(3)$ & $x(4)$ & 50,356 & 30,239 \\
\hline Aruba & 2010 & $\ldots$ & $\ldots$ & 105 & 71 \\
\hline Belice (2) & 2010 & 5 & 3 & 65 & 39 \\
\hline Bolivia & 2009 & 15,883 & 8,645 & 30,385 & 15,342 \\
\hline Brasil & 2010 & 884,826 & 467,215 & 814,142 & 463,936 \\
\hline Islas Caimán & 2010 & . & . & 172 & 126 \\
\hline Chile & 2011 & 8,951 & 3,286 & 46,620 & 21,911 \\
\hline Colombia & 2010 & 127,077 & $x(1)$ & $\ldots$ & $\ldots$ \\
\hline Costa Rica (1) & 2010 & 19,084 & 10,002 & 10,359 & 6,099 \\
\hline Cuba & 2010 & 9,327 & 3,855 & 120,112 & 63,628 \\
\hline Dominica & 2011 & . & . & . & . \\
\hline Rep. Dominicana & 2010 & 32,106 & 16,803 & 13,117 & 8,131 \\
\hline Ecuador & 2010 & $\ldots$ & $\ldots$ & 19,661 & 10,068 \\
\hline El Salvador & 2010 & . & . & . & . \\
\hline Guatemala & 2011 & . & . & . & . \\
\hline Honduras & 2010 & 5,624 & 3,261 & . & . \\
\hline Jamaica (1) & 2010 & $\ldots$ & $\ldots$ & - & - \\
\hline México & 2010 & 387,650 & 202,701 & . & . \\
\hline Nicaragua & 2010 & 21,185 & 11,818 & 21,118 & 12,444 \\
\hline Panamá & 2010 & $\ldots$ & $\cdots$ & $\cdots$ & $\cdots$ \\
\hline Paraguay & 2010 & 13,717 & 7,268 & 31,579 & 17,182 \\
\hline Perú & 2010 & $\ldots$ & $\ldots$ & $\ldots$ & $\ldots$ \\
\hline Puerto Rico (1) & 2010 & 2,425 & $x(1)$ & 2,494 & $\mathrm{x}(9)$ \\
\hline Santa Lucia & 2010 & $\ldots$ & $\ldots$ & $\ldots$ & $\ldots$ \\
\hline Trinidad and Tobago (1) & 2010 & $\cdots$ & $\cdots$ & $\ldots$ & $\ldots$ \\
\hline Uruguay (1) & 2010 & $\ldots$ & $\ldots$ & $\ldots$ & $\ldots$ \\
\hline Venezuela & 2010 & 40,370 & 20,071 & 47,372 & 24,904 \\
\hline
\end{tabular}




\section{Matrícula de educación primaria y secundaria de adultos por sexo y edad}

\begin{tabular}{|c|c|c|c|c|c|c|c|c|c|c|c|c|c|}
\hline \multirow[b]{4}{*}{ País o territorio } & \multirow{4}{*}{$\begin{array}{c}\text { Año de } \\
\text { referencia }\end{array}$} & \multicolumn{6}{|c|}{ Educación primaria } & \multicolumn{6}{|c|}{ Educación secundaria } \\
\hline & & \multicolumn{2}{|c|}{ Hasta 24 años } & \multicolumn{2}{|c|}{25 años y más } & \multicolumn{2}{|c|}{ Edad desconocida } & \multicolumn{2}{|c|}{ Hasta 24 años } & \multicolumn{2}{|c|}{25 años y más } & \multicolumn{2}{|c|}{ Edad desconocida } \\
\hline & & MF & $\mathbf{F}$ & MF & $\mathbf{F}$ & MF & $\mathbf{F}$ & MF & $\mathbf{F}$ & MF & $\mathbf{F}$ & MF & $\mathbf{F}$ \\
\hline & & (1) & (2) & (3) & (4) & (5) & (6) & (7) & (8) & (9) & (10) & (11) & (12) \\
\hline Antigua and Barbuda (1) & 2010 & - & - & - & - & - & - & $x(11)$ & $x(12)$ & $x(11)$ & $x(12)$ & 1,048 & 612 \\
\hline Argentina & 2010 & 166,228 & $x(6)$ & 79,792 & $x(6)$ & - & 125,338 & $x(11)$ & $x(12)$ & $x(11)$ & $x(12)$ & 522,289 & 269,800 \\
\hline Aruba & 2010 & $\ldots$ & $\ldots$ & $\ldots$ & $\ldots$ & $\ldots$ & $\ldots$ & 1,056 & 657 & 145 & 100 & - & - \\
\hline Belice (2) & 2010 & . & & . & . & . & . & 292 & 167 & 138 & 99 & - & - \\
\hline Bolivia (Estado Plurinacional de) & 2009 & 23,564 & 15,983 & - & - & 750 & 370 & 99,937 & 48,654 & - & - & 2,137 & 1,176 \\
\hline Brasil & 2010 & 218,473 & 73,871 & 739,954 & 433,864 & 47 & 28 & $1,870,271$ & 765,322 & $1,496,369$ & 922,113 & 473 & 237 \\
\hline Islas Caimán & 2010 & . & r. & & & . & . & 36 & 21 & 136 & 105 & - & - \\
\hline Chile & 2011 & 3,504 & 928 & 5,868 & 2,131 & - & - & 110,864 & 45,730 & 33,825 & 16,957 & - & - \\
\hline Colombia & 2010 & 62,321 & 33,104 & 256,791 & 161,323 & 4,612 & 2,179 & 401,397 & 194,329 & 280,191 & 180,854 & 9,391 & 4,657 \\
\hline Costa Rica (1) & 2010 & 7,271 & 3,762 & 1,462 & 541 & - & - & 66,221 & 31,967 & 12,760 & 6,882 & - & - \\
\hline Cuba & 2010 & $x(5)$ & $x(6)$ & $x(5)$ & $x(6)$ & 11,254 & 1,486 & $x(11)$ & $x(12)$ & $x(11)$ & $x(12)$ & 311,075 & 148,837 \\
\hline Dominica & 2011 & $x(5)$ & $x(6)$ & $x(5)$ & $x(6)$ & 197 & 54 & $x(11)$ & $x(12)$ & $x(11)$ & $x(12)$ & 182 & 129 \\
\hline República Dominicana & 2010 & 36,799 & 14,147 & 18,264 & 12,160 & - & - & 86,332 & 43,385 & 44,848 & 30,009 & - & - \\
\hline Ecuador & 2010 & 2,908 & 1,304 & 2,222 & 1,400 & - & - & 165,608 & 88,880 & 45,658 & 26,218 & - & - \\
\hline El Salvador & 2010 & 4,375 & 1,730 & 2,024 & 881 & 53 & 27 & $\cdot$ & & . & . & . & \\
\hline Guatemala & 2011 & 66,625 & 46,449 & 178,276 & 149,760 & 8,073 & 3,369 & & & . & . & . & \\
\hline Honduras & 2010 & 35,618 & 17,364 & 38,637 & 19,929 & 28,580 & 14,895 & $x(11)$ & $x(12)$ & $x(11)$ & $x(12)$ & 27,398 & 14,727 \\
\hline Jamaica (1) & 2010 & $x(5)$ & $x(6)$ & $x(5)$ & $x(6)$ & 6,180 & 2,300 & $x(11)$ & $x(12)$ & $x(11)$ & $x(12)$ & 532 & 437 \\
\hline México & 2010 & 127,605 & 66,701 & 414,267 & 293,100 & - & - & 556,564 & 255,449 & 700,524 & 444,095 & - & - \\
\hline Nicaragua & 2010 & 44,190 & 20,208 & 59,564 & 33,377 & 1,484 & 551 & 126,257 & 64,200 & 21,187 & 11,601 & 60 & 34 \\
\hline Panamá & 2010 & $x(5)$ & $x(6)$ & $x(5)$ & $x(6)$ & 4,187 & 2,446 & $x(11)$ & $x(12)$ & $x(11)$ & $x(12)$ & 26,080 & 12,546 \\
\hline Paraguay & 2010 & 17,658 & 7,824 & 13,725 & 9,350 & - & - & 36,565 & 17,888 & 15,635 & 9,870 & - & - \\
\hline Perú & 2010 & 28,919 & 15,530 & 19,050 & 14,440 & - & - & 204,689 & 86,915 & 27,894 & 13,340 & - & - \\
\hline Puerto Rico (1) & 2010 & $x(5)$ & $x(6)$ & $x(5)$ & $x(6)$ & 3,152 & 961 & $x(11)$ & $x(12)$ & $x(11)$ & $x(12)$ & 19,107 & 7,709 \\
\hline Santa Lucia & 2010 & . & r & . & . & . & . & $x(11)$ & $x(12)$ & $x(11)$ & $x(12)$ & 820 & 555 \\
\hline Trinidad and Tobago (1) & 2010 & $x(5)$ & $x(5)$ & $x(5)$ & $x(5)$ & 491 & $x(5)$ & $x(11)$ & $x(11)$ & $x(11)$ & $x(11)$ & 6,031 & $x(11)$ \\
\hline Uruguay (1) & 2010 & $x(5)$ & $x(6)$ & $x(5)$ & $x(6)$ & 2,803 & 1,503 & $x(11)$ & $x(11)$ & $x(11)$ & $x(11)$ & 56,466 & $x(11)$ \\
\hline Venezuela (República Bolivariana de) & 2010 & 8,668 & 4,096 & 4,022 & 2,363 & - & - & 152,671 & 72,784 & 53,274 & 30,512 & - & - \\
\hline
\end{tabular}

